Article

\title{
Insights into the Histone Acetylation-Mediated Regulation of the Transcription Factor Genes That Control the Embryogenic Transition in the Somatic Cells of Arabidopsis
}

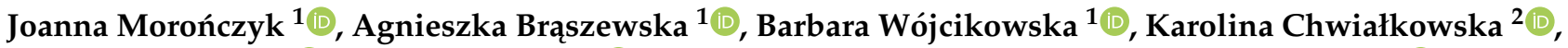 \\ Katarzyna Nowak ${ }^{1}\left(\mathbb{D}\right.$, Anna M. Wójcik ${ }^{1}\left(\mathbb{D}\right.$, Mirosław Kwaśniewski ${ }^{2}$ and Małgorzata D. Gaj ${ }^{1, *(D)}$
}

1 Institute of Biology, Biotechnology and Environmental Protection, Faculty of Natural Sciences, University of Silesia in Katowice, 40-007 Katowice, Poland; joanna.moronczyk@us.edu.pl (J.M.); agnieszka.braszewska@us.edu.pl (A.B.); barbara.wojcikowska@us.edu.pl (B.W.); katarzyna.nowak@us.edu.pl (K.N.); anna.wojcik@us.edu.pl (A.M.W.)

2 Centre for Bioinformatics and Data Analysis, Medical University of Bialystok, 15-269 Bialystok, Poland; karolina.chwialkowska@umb.edu.pl (K.C.); miroslaw.kwasniewski@umb.edu.pl (M.K.)

* Correspondence: malgorzata.gaj@us.edu.pl

check for updates

Citation: Morończyk, J.; Brąszewska, A.; Wójcikowska, B.; Chwiałkowska, K.; Nowak, K.; Wójcik, A.M.; Kwaśniewski, M.; Gaj, M.D. Insights into the Histone AcetylationMediated Regulation of the Transcription Factor Genes That Control the Embryogenic Transition in the Somatic Cells of Arabidopsis. Cells 2022, 11, 863. https://doi.org/ $10.3390 /$ cells 11050863

Academic Editors: Keqiang Wu and Francesco Carimi

Received: 13 December 2021

Accepted: 28 February 2022

Published: 2 March 2022

Publisher's Note: MDPI stays neutral with regard to jurisdictional claims in published maps and institutional affiliations.

Copyright: (C) 2022 by the authors. Licensee MDPI, Basel, Switzerland. This article is an open access article distributed under the terms and conditions of the Creative Commons Attribution (CC BY) license (https:// creativecommons.org/licenses/by/ $4.0 /)$.

\begin{abstract}
Somatic embryogenesis (SE), which is a process that involves the in vitro-induced embryogenic reprogramming of plant somatic cells, requires dynamic changes in the cell transcriptome. These changes are fine-tuned by many genetic and epigenetic factors, including posttranslational histone modifications such as histone acetylation. Antagonistically acting enzymes, histone acetyltransferases (HATs) and deacetylases (HDACs), which control histone acetylation in many developmental processes, are believed to control SE. However, the function of specific HAT/HDACs and the genes that are subjected to histone acetylation-mediated regulation during SE have yet to be revealed. Here, we present the global and gene-specific changes in histone acetylation in Arabidopsis explants that are undergoing SE. In the TSA (trichostatin A)-induced SE, we demonstrate that H3 and H4 acetylation might control the expression of the critical transcription factor $(T F)$ genes of a vital role in SE, including LEC1, LEC2 (LEAFY COTYLEDON 1; 2), FUS3 (FUSCA 3) and MYB118 (MYB DOMAIN PROTEIN 118). Within the HATs and HDACs, which mainly positively regulate SE, we identified HDA19 as negatively affecting SE by regulating LEC1, LEC2 and BBM. Finally, we provide some evidence on the role of HDA19 in the histone acetylation-mediated regulation of LEC2 during SE. Our results reveal an essential function of histone acetylation in the epigenetic mechanisms that control the TF genes that play critical roles in the embryogenic reprogramming of plant somatic cells. The results implicate the complexity of Hac-related gene regulation in embryogenic induction and point to differences in the regulatory mechanisms that are involved in auxin- and TSA-induced SE.
\end{abstract}

Keywords: Arabidopsis; auxin; histone acetylation; somatic embryogenesis; transcription factors; trichostatin A

\section{Introduction}

Chromatin, which is a complex of DNA and histones, plays a central role in controlling the gene expression at the transcriptional level by modulating the accessibility of DNA to the transcription factors (TFs) [1]. Dynamic changes in the chromatin structure are orchestrated by epigenetic modifications, including DNA methylation and the posttranslational modifications of histones such as acetylation, methylation and phosphorylation [2].

In contrast to DNA methylation, the role of the histone modification, including histone acetylation (Hac), in regulating gene expression is less recognised, primarily because of the limited number of available analytical tools [3]. In recent years, new molecular methods applied in epigenetics have contributed to significant progress in revealing experimental evidence about the essential role of histone modifications, including Hac, in regulating the 
gene expression in various organisms, including plants [4,5]. During the Hac-mediated regulation of gene expression, histone acetyltransferases (HATs) neutralise the positive charge of lysine in the histone tails, and that, in turn, promotes an "open" and transcriptionally permissive chromatin structure [6]. Conversely, histone deacetylases (HDACs) restore the positive charge of the lysine in histones, which triggers chromatin condensation and negatively affects gene expression [7]. In order to activate or repress the target gene expression, HATs and HDACs act as a part of the transcriptional complexes and control many developmental processes in plants [8]. In addition to functioning in the transcriptional complexes, HATs and HDACs might also control the de/acetylation state of the non-histone proteins [8,9].

In eukaryotes, epigenetic modifications control diverse developmental processes, including the extensive transcriptome reprogramming that is associated with changes in the cell fate [10,11]. It is believed that dedifferentiated cells have an open state of chromatin that enables re-differentiation, while compact chromatin is required to stabilise the gene expression and to maintain the identity of the differentiated cells [12,13].

During somatic embryogenesis (SE), a plant-specific developmental process, the embryogenic transition that is induced in the in vitro-cultured and differentiated plant somatic cells results in embryo-like structures, i.e., somatic embryos that efficiently regenerate into plants. SE-based plant regeneration systems are widely used in biotechnology for the micropropagation and genetic transformation of different plant species [14]. Thus, understanding the molecular processes that control the embryogenic switch in somatic plant cells is of interest to current plant biotechnology. The extensive reprogramming of the cell transcriptome that is associated with SE induction involves erasing or bypassing the existing cell fate memory under the control of epigenetic modifications $[15,16]$. Most reports on the epigenetic control of SE concern DNA methylation [17]. Both the hypo- and hypermethylation of DNA have been attributed to SE induction, and changes in DNA methylation have also been postulated to regulate the TF genes that have a function in the embryogenic response [18-20]. To regulate gene expression, DNA methylation interplays with histone modifications, and, within them, histone methylation has been the most frequently investigated in in vitro-cultured plant tissue [21-23]. Histone methylation, which is catalysed by the POLYCOMB REPRESSIVE COMPLEX 2 (PRC2), has been reported to control several of the TF genes that are involved in cell differentiation and SE induction [24].

The function of Hac in regulating genes during in vitro-induced plant morphogenesis remains much less recognised and mainly only indirect evidence has been reported. The impaired function of histone acetyltransferases and deacetylases negatively affect the morphogenic responses, including callus formation and shoot regeneration in in vitro-cultured plant cells/tissue [25-28]. Moreover, the differential expression of the HAT and HDAC genes in embryogenic cultures of Arabidopsis and Hevea brasiliensis indirectly implies that dynamic epigenetic changes accompany SE induction $[29,30]$. Similarly, microsporederived embryos of Brassica napus had an elevated level of BnHAT, which corresponded to an increased accumulation of the H3ac and H4ac epigenetic marks [31]. In Pinus radiata, the higher capacity for the in vitro shoot organogenesis of immature needles than for mature needles was attributed to a higher level of H4ac [32].

Experiments with trichostatin A (TSA), which is an inhibitor of the zinc-dependent HDACs [33], provided evidence on the role of Hac in the regulation of SE in plants. Accordingly, TSA treatment increased the embryogenic responses that were induced in vitro in cultures of various plants, including conifers, cereals and dicots [34-36]. The SE-promoting effect of TSA treatment has also been indicated in the model plant Arabidopsis and its TSAinduced seedlings and explants developed somatic embryos on auxin-free media [37,38]. It is worth noting that the TSA-induced embryogenic response in Arabidopsis was accompanied by changes in the gene expression, which suggests that Hac might contribute to SE induction via the deregulation of the genes that are involved in the embryogenic transition [37,38]. 
The genes that have an essential function in embryogenic induction encode several hormone- and stress-related transcription factors (TFs) that play central regulatory roles in both zygotic and somatic embryogenesis, including LEAFY COTYLEDON 1;2 (LEC1 and LEC2), FUSCA3 (FUS3), BABY BOOM (BBM), AGAMOUS-LIKE15 (AGL15), WUSCHEL (WUS) and MYB118 (MYB DOMAIN PROTEIN 118) [39,40]. LEC1 encodes the HAP3 subunit of the CCAAT box-binding factor, while LEC2 represents a plant-specific family of TFs with a highly conserved B3 domain [41,42]. The LEC1- and LEC2-mediated mechanisms of SE induction involve activating the auxin biosynthesis YUCCA genes [43-45]. In SE induction, LEC1 and LEC2 are transcriptionally regulated by the BBM TF that is a member of the AINTEGUMENTA-LIKE (AIL) subfamily and contains two AP2/ERF (APETALA2/ethylene-responsive element) domains [46]. LEC2 also interacts with AGL15 of the MADS-box family of TFs to control the GA/ABA balance in SE induction $[47,48]$. AGL15, when ectopically expressed, leads to the formation of somatic embryos by controlling hormonal signalling during SE induction $[49,50]$. In zygotic embryogenesis (ZE), LEC2 targets $M Y B 118$ of the $M Y B$ gene family in order to regulate the biosynthesis of the storage compounds and the LATE EMBRYOGENESIS ABUNDANT (LEA) genes [51,52]. In addition to $M Y B 118, M Y B 115$, by controlling the embryo storage products, also promotes an embryogenic transition in Arabidopsis [53]. Moreover, the WUS of the plant-specific homeobox superfamily of WOX TFs of a critical role in determining stem cell fate in the shoot apical meristem (SAM) of higher plants has also been attributed to the SE-regulatory network [54,55]. The early auxin gradient-dependent expression of WUS in the embryogenic callus of Arabidopsis was associated with somatic embryo development [56].

Evidence for the role of Hac in regulating the SE-associated TFs remains limited. It involves the role of HDA6 and HDA19 in the repression of the seed maturation TFs, including LEC1, LEC2, FUS3 and ABI3 (ABA INSENSITIVE 3) during seedling development [57-59]. Similarly, LEC1, FUS3 and ABI3 were deregulated in an HDA6/19:RNAi repression line of Arabidopsis that developed somatic embryos on the seedlings [37]. Further analysis is required to provide direct evidence on the role of Hac in controlling the genes of the SE-regulatory network that govern the embryogenic transition in plant somatic cells.

Here, we gained insights into the global and gene-specific changes in the acetylation of the histones that are associated with the embryogenic transition that is induced in Arabidopsis explants in response to auxin and TSA treatment. The global changes in the acetylation of $\mathrm{H} 3$ histone in the SE-induced explants were monitored using ELISA and the immunohistochemical approaches. Moreover, in order to assess the role of Hac in controlling the SE-involved TFs, the $\mathrm{H} 3 / \mathrm{H} 4$ acetylation status of the chromatin that was bound to LEC1, LEC2, FUS3, MYB118, BBM, AGL15 and WUS was analysed using the ChIP-qPCR method.

The results provide several experimental pieces of evidence on the function of Hac in controlling the embryogenic transition in plant somatic cells. The changes in the global Hac level, which are associated with the deregulation of numerous HAT and HDAC genes, were demonstrated in the SE-induced explants. The role of HDA19 in regulating the SE-TFs was shown and a correlation between the gene expression and $\mathrm{H} 3 / \mathrm{H} 4 \mathrm{ac}$ was indicated for the master regulators of SE, including LEC (LEC1, LEC2 and FUS3) during TSA-induced SE. Moreover, we provided evidence on the role of HDA19 in controlling the LEC2 expression in SE induction.

\section{Materials and Methods}

\subsection{Plant Material}

Arabidopsis thaliana (L.) Heynh. plants of the Columbia (Col-0) and Wassilewskija (Ws2) WT ecotypes, the insertional mutant lines and the RNAi transgenic lines were used in the study (Tables S1 and S2). The seeds were purchased from the Nottingham Arabidopsis Stock Centre (NASC), Nottingham University, Nottingham, UK or were kindly provided by Dr. Kim Boutilier (Bioscience, Wageningen University and Research, Wageningen, Netherlands), Prof. Konstantinos Vlachonasios (School of Biology, Aristotle University 
of Thessaloniki, Thessaloniki, Greece) and Prof. Keqiang Wu (Institute of Plant Biology, National Taiwan University, Taipei, Taiwan). The homozygous mutants were selected according to the NASC standard protocol (http://signal.salk.edu/tdnaprimers.2.html; accessed on 28 February 2022).

\subsection{Plant Growth and In Vitro Culture Conditions}

The plants that were used as the source of the explants were grown in Jiffy-7 peat pots (Jiffy, Zwijndrecht, Netherlands) in a "walk-in" type phytotron under controlled conditions at $20-22{ }^{\circ} \mathrm{C}$ under a $16 / 8 \mathrm{~h}$ (light/dark) photoperiod of $100 \mu \mathrm{M} \mathrm{m}^{-2} \mathrm{~s}^{-1}$ white fluorescent light. The in vitro-grown plant material was then maintained at $20^{\circ} \mathrm{C}$ under a $16 / 8 \mathrm{~h}$ (light/dark) photoperiod of $40 \mu \mathrm{M} \mathrm{m}^{-2} \mathrm{~s}^{-1}$ white fluorescent light.

\subsection{In Vitro Culture of the Explants}

The explants, immature zygotic embryos (IZEs) at the cotyledonary stage of development, were cultured in vitro on different media or were immediately used as the control $(0 \mathrm{~d})$ for the molecular analysis. To obtain the explants for the in vitro cultures, the IZEs were manually isolated from the siliques under a stereomicroscope and transferred onto the culture media.

The basal E0 medium contained $3.2 \mathrm{~g} \mathrm{~L}^{-1}$ of B5 micro- and macro-elements (Duchefa Biochemie, Haarlem, Netherlands, \#G0210), $20 \mathrm{~g} \mathrm{~L}^{-1}$ sucrose and $8 \mathrm{~g} \mathrm{~L}^{-1}$ agar, $\mathrm{pH}$ 5.8. For the SE induction, an EA medium based on the E0 medium that had been supplemented with $5.0 \mu \mathrm{M}$ of 2,4-D (Duchefa Biochemie, Haarlem, Netherlands, \#D0911) was applied following the standard protocol for SE induction in Arabidopsis [60]. Additionally, an E0 medium that had been supplemented with $1.0 \mu \mathrm{M}$ of TSA (ET) (Sigma-Aldrich, St. Louis, MO, USA, \#T1952) was also used.

The capacity for SE was evaluated in three-week-old cultures. Two parameters of embryogenic potential were evaluated: SE efficiency (the frequency of the explants that produced somatic embryos) and SE productivity (the average number of somatic embryos that developed per embryogenic explant). In order to evaluate SE efficiency and SE productivity, 10 explants were cultured in one Petri dish and 30 explants from each culture combination in at least three replicates were analysed.

The explants that were cultured on the E0, EA and ET media for 0, 5 and 10 days were sampled for molecular analysis using the different methods (Table S3).

\subsection{Histone Extraction}

The histone proteins were isolated from the explants that had been cultured on the E0, EA and ET media for 0, 5 and 10 days using a commercially available kit according to the manufacturer's protocol (Abcam, Cambridge, UK, \#ab113476). The protein concentration was estimated using the Bradford assay with a Pierce Coomassie (Bradford) Protein Assay Kit (Thermo Fisher Scientific, Waltham, MA, USA, \#23200) and the absorbance was measured using a Tecan Infinite M200 Microplate reader (Tecan, Männedorf, Switzerland) in a Bio-one Cellstar 96-well plate (Greiner, Kremsmünster, Austria) at a $595 \mathrm{~nm}$ wavelength. The samples were stored at $-80^{\circ} \mathrm{C}$.

\subsection{ELISA}

The colourimetric ELISA method was used to analyse the total histone $\mathrm{H} 3$ acetylation in the different histone extracts, following the manufacturer's protocol for a commercially available kit (Abcam, Cambridge, UK, \#ab115124). The colourimetric absorbance was measured in a Tecan Infinite M200 Microplate reader at a $450 \mathrm{~nm}$ wavelength. The amount of acetylated $\mathrm{H} 3$ was calculated as the $\mathrm{ng} / \mathrm{mg}$ protein. Wells without the antigen were used as the blank control. Three biological and two technical replicates of each culture combination were analysed for the total histone $\mathrm{H} 3$ acetylation content. 


\section{6. $C h I P-q P C R$}

The embryogenic culture of Arabidopsis was analysed using the ChIP method according to Nowak et al. [61]. A complex of proteins and DNA fragments were immunoprecipitated using the polyclonal antibodies against the acetylated forms of histone H3, H3K9/K14ac (2 $\mu$; Sigma-Aldrich, St. Louis, MO, USA, \#06-599) and histone H4, H4K5/K8/K12/K16ac (2 $\mu \mathrm{g}$; Sigma-Aldrich, St. Louis, MO, USA, \#06-866). For each sample, a negative control (mock) that had no antibody was analysed. The DNA that cross-linked to the immunoprecipitated proteins was reversed and $1 \mu \mathrm{L}$ of ChIPed DNA was analysed with qPCR using the gene-specific primers (Table S4). The primers for qPCR for the genomic sequences that were located approximately $300 \mathrm{bp}$ downstream of the transcription start site (TSS+300 bp) were designed in the Primer3Plus software [62]. The primers for ACTIN7 (AT5G09810) were used according to Luo et al. [63]. A LightCycler 480 (Roche, Basel, Switzerland) real-time detection system was used to analyse the acetylation level of the chromatin that was associated with the analysed genes. The qPCR analysis followed Wójcikowska and Gaj [64]. The Ct values were calculated in LinRegPCR software [65]. The ChIP-qPCR data were normalised to the values that had been obtained for the internal control (ACTIN7) and the data are presented using the $2^{\Delta \mathrm{Ct}}$ method where $\Delta \mathrm{Ct}$ represents the $\mathrm{Ct}_{A C T I N 7}-\mathrm{Ct}_{\text {gene of interest }}$. Three biological replicates and two technical replicates were analysed.

\subsection{Immunohistochemistry}

The explants were fixed in $4 \%$ formaldehyde in PBS and placed in a vacuum desiccator for two hours. The procedures for embedding the tissue in Steedman's wax and for preparing the slides were previously described by Wolny et al. [66]. The tissue was cut to 5 $\mu \mathrm{m}$-thick tissue sections on a Zeiss Hyrax M40 rotary microtome (Zeiss, Oberkochen, Germany), placed on poly-L-lysine-coated slides and stretched by adding a small drop of water. The immunostaining was conducted as was described by Braszewska-Zalewska et al. [67]. The polyclonal antibody against the acetylated form of histone H3 (H3K9/K14ac; 1:200; Sigma-Aldrich, St. Louis, MO, USA, \#06-599) and Alexa Fluor 488 goat anti-rabbit IgG (1:200; Thermo Fisher Scientific, Waltham, MA, USA, \#A-11008) as the secondary antibody were used. The slides were mounted and counterstained in Vectashield (Vector Laboratories, Burlingame, CA, USA, \#H-1000) that contained $2.5 \mu \mathrm{g} / \mathrm{mL}$ DAPI. The DAPI fluorescence (excitation $405 \mathrm{~nm}$, emission 425-475 nm) and Alexa 488 (excitation $488 \mathrm{~nm}$, emission 500-600 nm) were registered using an Olympus FV1000 confocal system (Olympus, Tokyo, Japan) that was equipped with an Olympus IX81 inverted microscope. The images were processed using the ImageJ Fiji package. The fluorescence intensity of the Alexa 488 and DAPI was measured as the mean values from the Integrated Density (IntDen) parameter per the nuclei that represented the sum of all of the pixels within the region of interest. The eight-bit images with the Alexa 488 and DAPI fluorescence were segmented with the threshold value parameter. The results of these measurements were estimated in relative units as the mean values and 2-4 biological replicates were analysed per combination.

\subsection{Reverse Transcription and RT-qPCR Analyses}

An RNAqueous Total RNA Isolation Kit (Thermo Fisher Scientific, Waltham, MA, USA) was used to isolate the total RNA from the IZE explants that had been induced on the EA medium for 0, 5 and 10 days according to the manufacturer's instructions. The concentration and purity of the RNA samples were evaluated using an ND-1000 spectrophotometer (NanoDrop Technologies, Wilmington, DE, USA). The RNA samples were treated with RQ1 RNase-free DNase I (Promega, Madison, WI, USA) according to the manufacturer's instructions. The first-strand cDNA was synthesised using a RevertAid First Strand cDNA Synthesis Kit with an oligo-dT primer according to the manufacturer's instructions (Thermo Fisher Scientific, Waltham, MA, USA). The obtained cDNA was diluted five-fold with water and used at a volume of $2.5 \mu \mathrm{L}$ for the RT-qPCR, which was conducted according to Wójcikowska and Gaj [64]. A LightCycler 480 SYBR Green I Master 
(Roche, Basel, Switzerland) and the primers that were relevant to the genes being studied were used to determine the RT-qPCR reactions (Table S5). The Ct values were calculated in LinRegPCR software [65]. The relative gene expression levels were calculated and normalised to the internal control, the TIN (AT4G27090) gene, which encodes the 60S ribosomal protein [68]. The relative expression level was calculated using $2^{-\Delta \Delta C t}$ where $\Delta \Delta \mathrm{Ct}$ represented $\Delta \mathrm{Ct}$ reference condition $-\Delta \mathrm{Ct}^{\text {compared condition }}$. Three biological replicates and two technical replicates were analysed.

\subsection{RNA Isolation, Library Preparation and Sequencing}

An RNAqueous Total RNA Isolation Kit (Thermo Fisher Scientific, Waltham, MA, USA) was used to isolate the total RNA from the IZE explants that had been induced on the different media (E0, EA, ET) for 0, 5 and 10 days according to the manufacturer's instructions. Depending on the age of the culture, $250(0 \mathrm{~d}), 200(5 \mathrm{~d})$ and $50(10 \mathrm{~d})$ explants were used to isolate the RNA. The concentration and purity of the RNA samples were evaluated using an ND-1000 spectrophotometer (NanoDrop Technologies, Wilmington, DE, USA). The integrity of the RNA was determined using an Agilent 2100 Bioanalyzer and Agilent RNA 6000 Nano chips (Agilent Technologies, Santa Clara, CA, USA). The RNA samples were treated with RNase-Free DNase and then purified with Acid-Phenol:Chloroform using the ammonium acetate method (Thermo Fisher Scientific, Waltham, MA, USA). The sequencing libraries were prepared using an Illumina ScriptSeq Complete Kit (Plant; Illumina, San Diego, CA, USA) following the manufacturer's protocol. $2 \mu \mathrm{g}$ of total RNA per sample were used as the input. Briefly, the library prep involved the following steps: removing the ribosomal RNA using Ribo-Zero rRNA Removal Reagents (Plant Leaf; Illumina, San Diego, CA, USA) followed by an ethanol precipitation of the rRNA-depleted sample, RNA fragmentation, cDNA synthesis, RNA removal, terminal tagging of the cDNA followed by a bead cleanup, PCR amplification using the Illumina indexes and a final bead purification. The quality of the prepared Illumina libraries was analysed using an Agilent Bioanalyzer with an Agilent High Sensitivity DNA Kit (Agilent Technologies, Santa Clara, CA, USA) and the quantities were estimated using a Qubit Fluorometer (Thermo Fisher Scientific, Waltham, MA, USA). To generate the clusters, the libraries were pooled at an equimolar concentration and sequenced using an Illumina HiSeq 4000 system (Illumina, San Diego, CA, USA) in the $2 \times 76$ cycles paired-end (PE) mode with six barcoded samples per lane.

\subsection{RNA-seq Data Analysis}

The sequencing data were processed in order to obtain fastq files with the bcl2fastq pipeline (Illumina, San Diego, CA, USA), including the demultiplexing and adapter trimming steps. The quality of the raw sequencing reads was evaluated with FastQC software (The Babraham Institute, Cambridge, United Kingdom) and all of the results were compared using the MultiQC tool [69]. As all of the reads were high quality, they were only soft-trimmed and filtered using Sickle [70]. Then, SortMeRNA was used to filter out any left-over fragments that had originated from the rRNAs [71]. The quality of the cleaned reads was assessed once again using FastQC and MultiQC. The cleaned reads were mapped to the Arabidopsis thaliana genome assembly GCA_000001735.1 (TAIR10) using the spliceaware aligner STAR [72] with the mapping parameters adjusted to the Arabidopsis genome characteristics, a basic two-pass mode and in order to permit 5\% of mismatches to the reference genome. The unique counts per gene were calculated in a built-in option in STAR and were used to analyse any further differential gene expression. The mapping quality was assessed using the SAMStat package [73] and Qualimap [74]. The sequence alignment files were indexed using SAMtools [75] and the mapped reads were visually inspected using an Integrative Genomics Viewer [76]. All of the further computational and graphical analyses were performed in the $R$ environment. The size factors of the samples were estimated using the median ratio method and the counts were normalised using the DESeq2 algorithm [77]. To inspect and visualise the data, the counts were regularised and log-transformed (rlog) in order to obtain the log2-scaled data that were approximately 
homoscedastic and normalised with respect to the library size. The differential expression was analysed with DESeq2 software [77], assuming a negative binomial distribution and using a general linearised model with prior beta shrinkage. Wald's exact test was used to identify the differentially expressed genes (DEGs) under the $p$-value adjustment $(p<0.05)$ for multiple comparisons using the Benjamini-Hochberg False Discovery Rate (FDR) correction [78].

\subsection{Statistical Analysis}

The Student's $t$-test $(p<0.05)$ or two-way ANOVA analysis $(p<0.05)$ followed by Tukey's HSD test $(p<0.05)$ were used to determine any significant differences between the compared combinations. The graphs show the means with the standard deviations (SD).

\section{Results}

\subsection{An Increased H3ac Level Accompanies SE Induction}

In Arabidopsis, auxin treatment is required to induce SE in in vitro-cultured explants. However, we previously indicated that TSA treatment also resulted in SE induction on an auxin-free medium, which suggests that Hac plays a role in the mechanism that controls the embryogenic reprogramming of plant somatic cells [38]. To verify this hypothesis, we analysed the global H3ac level in Arabidopsis explants that had been induced toward SE on auxin (2,4-D)- and TSA-supplemented media, EA and ET, respectively. The control combinations included freshly isolated, non-induced explants $(0 \mathrm{~d})$ and explants that had been cultured on a non-embryogenic E0 medium.

The results of the ELISA test indicated significant differences in the global H3ac level between the control (E0) and embryogenic (ET, EA) cultures (Figure 1A). We found that the non-induced explants that had been cultured on the E0 medium had a transient ( $5 \mathrm{~d}$ ) reduction in global $\mathrm{H} 3$ acetylation. In contrast, no deacetylation of histones was observed in the SE explants that had been induced on the EA and ET media. In addition, the H3ac level was higher in the ET- than in the EA-induced explants.

Altogether, the results regarding the global changes in the $\mathrm{H} 3$ acetylation levels in the SE-induced explants suggested that both SE-induction treatments, auxin and TSA, affected the Hac level in the cultured explants.

\subsection{The Differential Spatio-Temporal Histone H3ac Pattern in the SE-Induced Explants}

Next, the immunohistochemical approach was used to examine the spatio-temporal H3ac pattern during SE. To obtain a general view of the Hac pattern in the in vitro-cultured explants, we examined the distribution of $\mathrm{H} 3 \mathrm{ac}$ in the freshly isolated $(0 \mathrm{~d})$ and in the in vitro-cultured explants (EA, ET and E0). In the control E0 culture, the analysis was limited to the fifth day because the explants that had been cultured for 10 days had developed into seedlings.

The results indicated that there were H3ac signals in different explant parts, including in the cotyledons, SAM and hypocotyls (Figure 1B). Some differences in the general distribution pattern of Hac fluorescence were observed between the control and the SE-induced explants. In the freshly isolated $0 \mathrm{~d}$ explants, strong fluorescence signals were concentrated along with the vascular tissue in the hypocotyl (Figure 1B; a-a') while at $5 \mathrm{~d}$ of E0 culture, a strong Hac was detected in the SAM area (Figure 1B; b- $\mathbf{b}^{\prime}$ ). Strong SAM-associated Hac signals were also observed in the SE-induced explants, particularly in the early $5 \mathrm{~d}$ culture (Figure 1B; $\left.\mathrm{c}-\mathrm{c}^{\prime}, \mathrm{e}-\mathrm{e}^{\prime}\right)$. Unlike the E0, the SE-induced explants had signals that were more dispersed in the whole explant, which were distributed evenly in the hypocotyl and cotyledons. Therefore, we assumed that the explant parts with intensively enriched Hac signals, including the hypocotyls and SAM, primarily contributed to changes in the global $\mathrm{H} 3 \mathrm{ac}$ that was detected in the ELISA assay (Figure 1A). 

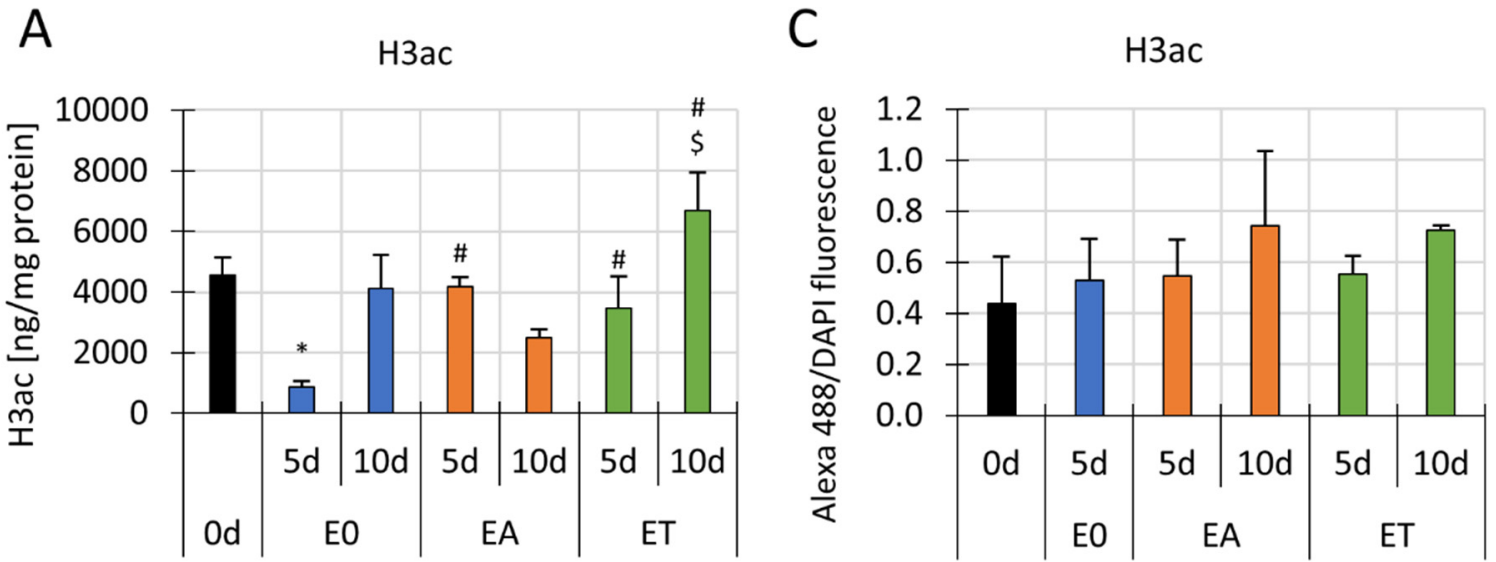

B

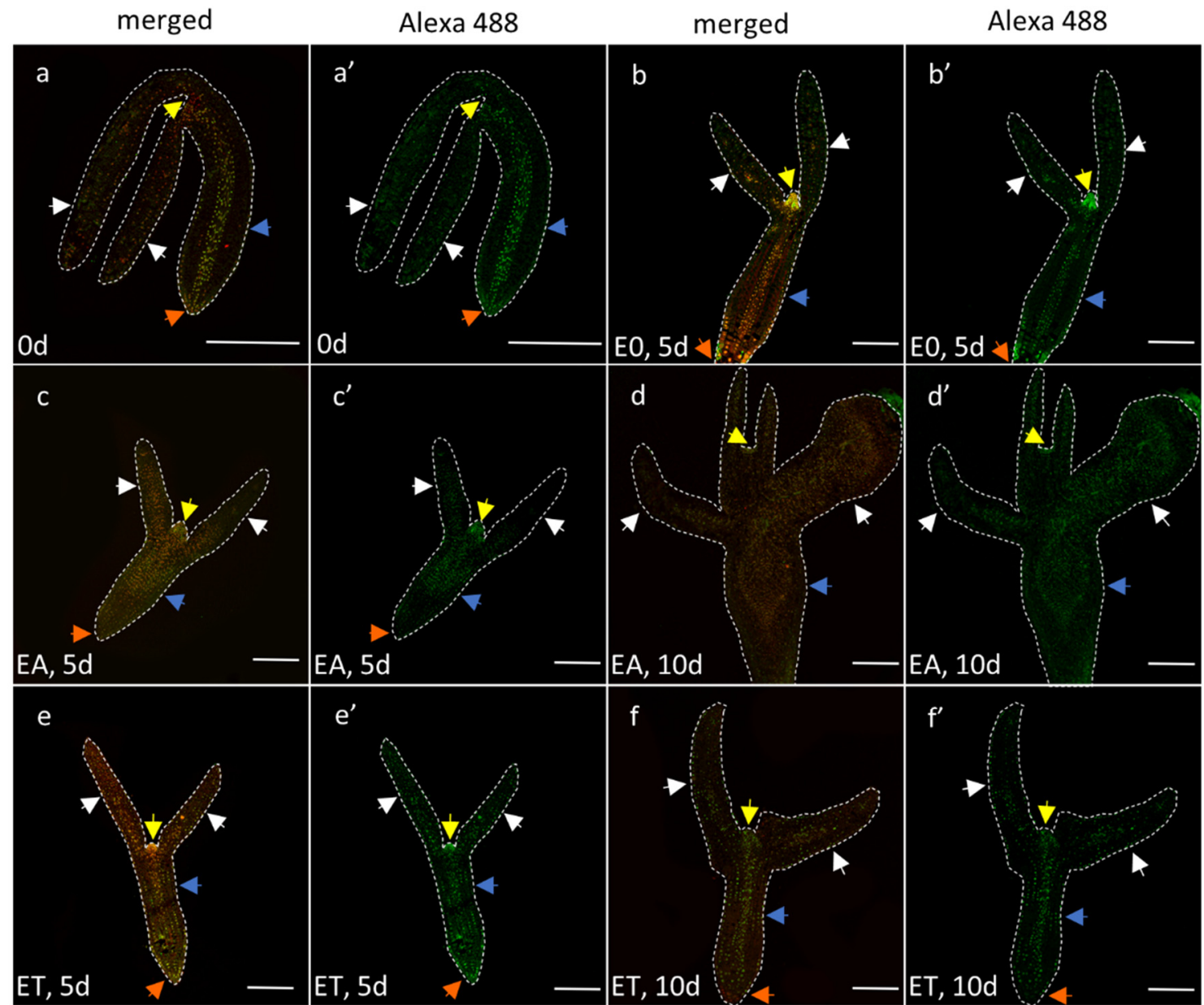

Figure 1. Analysis of H3a in SE. (A) Total histone $\mathrm{H} 3$ acetylation (H3ac) level in the freshly isolated and in vitro-cultured explants of Col-0. The explants were induced on E0, EA and ET media for 5 and 10 days. The amount of the acetylated form of histone $\mathrm{H} 3$ was calculated as the $\mathrm{ng} / \mathrm{mg}$ of protein. (B) Immunodetected spatio-temporal pattern of Hac in the Col-0 explants and immature zygotic embryos that had been cultured on different media (EA, ET, E0). H3ac-signals in longitudinal sections of the freshly isolated $0 \mathrm{~d}$ explants $\left(\mathrm{a}, \mathrm{a}^{\prime}\right)$ and the explants that had been cultured for 5 and 10 days on different media, including E0 (b, b'), EA (c, $\left.c^{\prime}, d, d^{\prime}\right)$ and ET (e, e', f, $\left.f^{\prime}\right)$. Coloured arrows point to the cotyledon (white), SAM (yellow), RAM (orange) and hypocotyl (blue). Red (computer altered)_DAPI; green (computer altered)—Alexa 488 (immunostaining of H3ac). Scale bar represents 
$200 \mu \mathrm{m}$. (C) The intensity of Alexa 488 (H3ac) fluorescence in the cell nuclei of the explant cotyledons was normalised to the fluorescence of DAPI (DNA) and data are presented as the Alexa 488/DAPI ratio. (A,C) A two-way ANOVA analysis $(p<0.05)$ followed by Tukey's HSD $(p<0.05)$ was used to determine any values that were significantly different from $0 \mathrm{~d}(*)$; the E0 culture at the same age (\#); the EA culture at the same age $(\$)(n=2-4$; means \pm SD are given).

In the SE-induced IZE explants of Arabidopsis, somatic embryos are produced exclusively on the adaxial side of the cotyledons in close proximity to the SAM, while the rest of the explant tissue, including the hypocotyl, SAM and RAM (root apical meristem) are not involved in SE [79]. Therefore, we gained a better insight into the SE-involved cotyledons and we compared the intensity of the Hac signals between the treatments in the selected areas of the tissue (Figure S1). The results indicated that there were no significant differences in the $\mathrm{H} 3 \mathrm{ac}$ fluorescence signals in the SE-involved cotyledonary tissue between the compared combinations (Table S6, Figure 1C).

Taken together, the results of the Hac immunohistochemical analysis indicated a spatiotemporal modulation of the H3ac signal in both the embryogenic and non-embryogenic cultures. In the SE-induced explants, the intense H3ac signals did not specifically colocalise with the SE-involved explant parts, i.e., the cotyledons. Moreover, the SE-induced cotyledons had levels that were similar to the control H3ac.

\subsection{Changes in H3 and H4 Acetylation in Gene-Bound Chromatin Are Associated with the Differential Transcription of the Key SE-Involved TF Genes in TSA-Induced SE}

Given that the TF genes with an SE-regulatory function are deregulated in the TSAinduced SE [37,38], we assumed that Hac might contribute to SE induction by controlling these genes. To address this critical issue, we analysed the relationship between the Hac and the expression levels of the SE-involved TFs, including LEC1, LEC2, FUS3, MYB118, $B B M, A G L 15$ and WUS in the embryogenic (ET, EA) vs. the control (E0) cultures. Using the ChIP-qPCR method, we evaluated the H3ac and H4ac enrichment in the chromatin that is associated with the TSS+300 bp fragments of the analysed genes. The effect of the auxin and TSA treatments on Hac and gene expression relative to the control E0 culture was evaluated.

The analysis indicated a significant increase in Hac in the chromatin that is associated with four of the analysed TF genes, LEC1, LEC2, FUS3 and MYB118 in the TSA-induced culture (Figure 2A-D). Consistent with this result, the TSA treatment also positively affected the expression level of the LEC1, LEC2, FUS3 and MYB118 genes, thus implying a positive relationship between Hac and the expression level of these genes (Figure $2 \mathrm{~A}^{\prime}-\mathrm{D}^{\prime}$ ). In contrast, the three other TF genes, BBM, AGL15 and WUS, which had a significantly increased expression in the embryogenic cultures (Figure S2 $\mathrm{A}^{\prime}-\mathrm{C}^{\prime}$ ), had similar H3ac and H4ac levels in both the embryogenic and non-embryogenic cultures (EA vs. E0; ET vs. E0) (Figure S2A-C).

Altogether, the result provided evidence on the role of Hac in controlling the TF genes with a regulatory function in the embryogenic response, including LEC1, LEC2, FUS3 and MYB118 during TSA-induced SE.

\subsection{Different Genes Encoding the Histone Acetyltransferase (HATs) and Deacetylases (HDACs) Are Involved in SE Induction}

The results regarding the changes in Hac in SE induction suggested the role of histone acetyltransferases (HATs) and deacetylases (HDACs) in controlling the SE transcriptome. Therefore, in order to identify the specific histone acetyltransferases and histone deacetylases that control SE induction, the expression patterns of the HAT and HDAC genes that are encoded in the Arabidopsis genome were analysed in the explants that had been induced on the different media (ET, EA and E0). Following the results regarding the HAT/HDACs profiling, the embryogenic capacity of the relevant hat and $h d a c$ mutants was evaluated. 
A

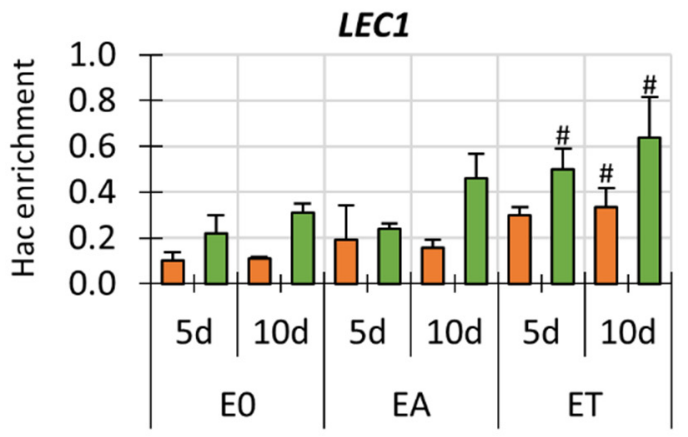

B

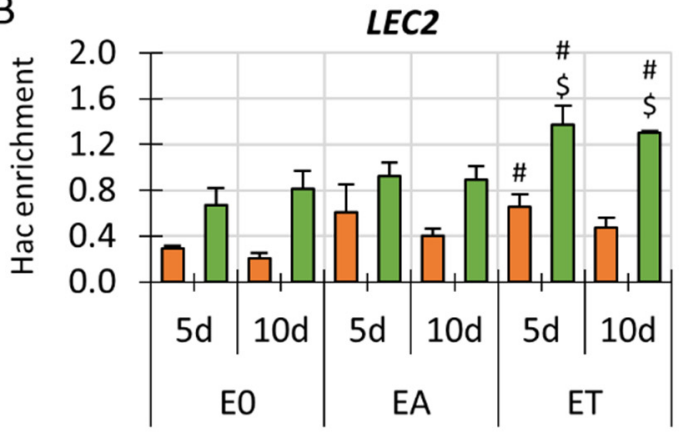

C

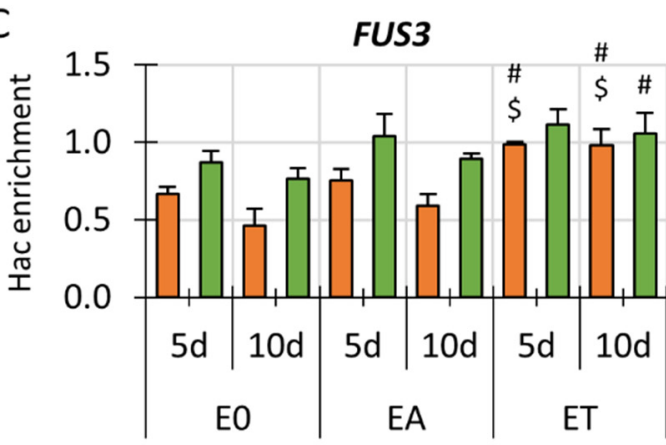

D

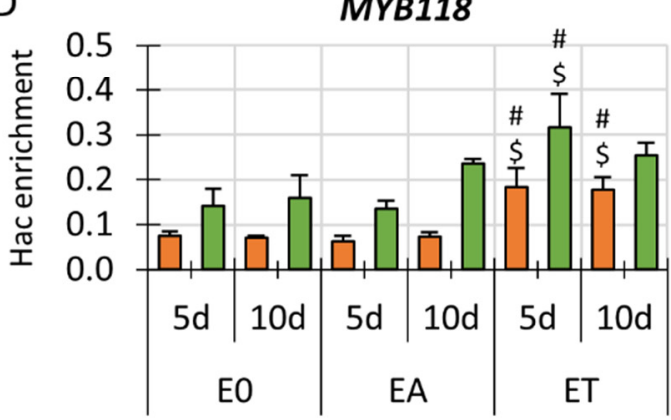

$A^{\prime}$

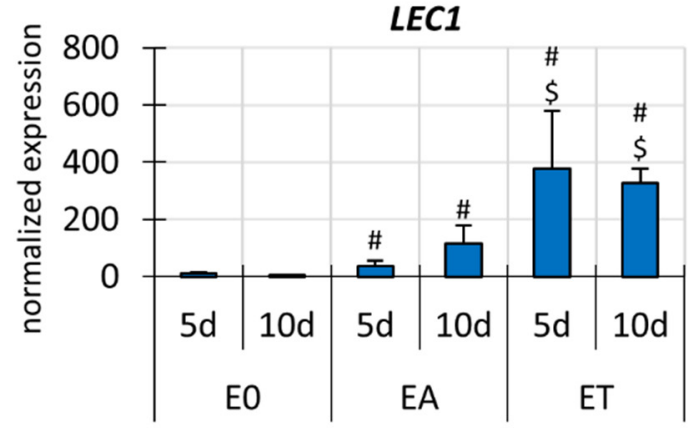

$B^{\prime}$

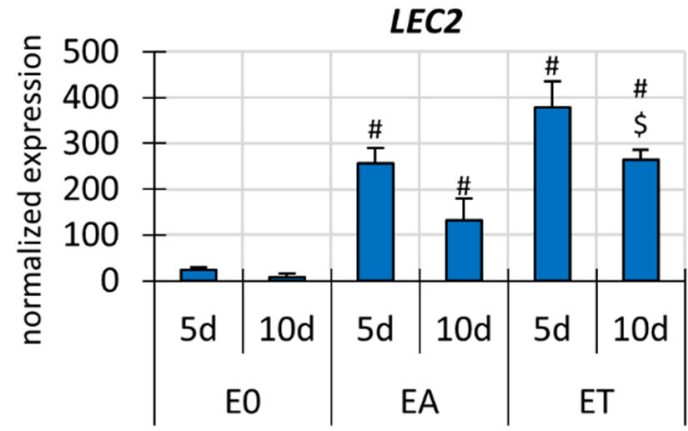

$C^{\prime}$

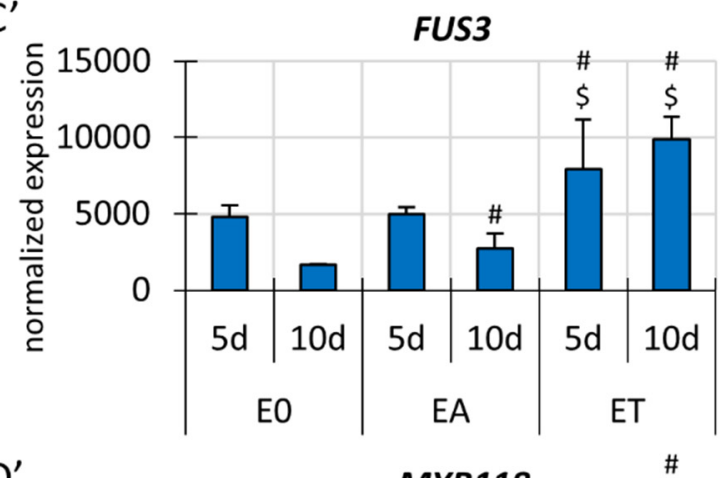

D'

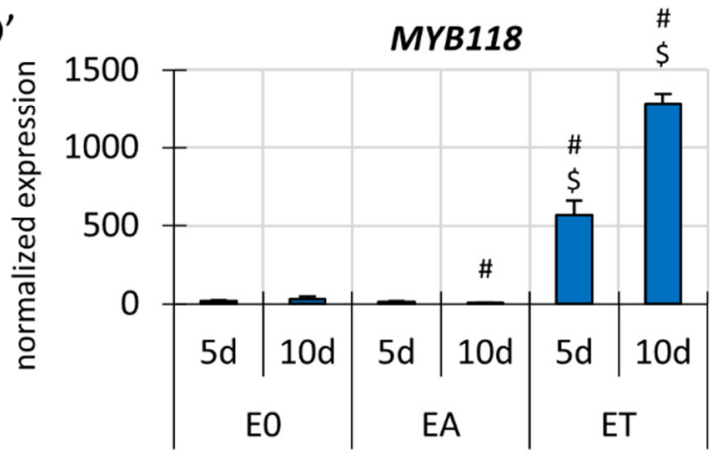

Figure 2. The H3ac and H4ac levels and expression profiles of LEC1 (A, $\left.\mathbf{A}^{\prime}\right)$, LEC2 (B, B'), FUS3 (C, $\left.\mathbf{C}^{\prime}\right)$ and MYB118 (D,D') in the Col-0 explants that had been cultured on the E0, EA and ET media for 5 and 10 days. Hac enrichment indicates the amount of DNA after ChIP that was normalised to the internal control (ACTIN7). ChIP-qPCR: a two-way ANOVA analysis $(p<0.05)$ followed by Tukey's HSD test $(p<0.05)$ were used to determine the values that were significantly different from the E0 culture at the same age (\#); the EA culture at the same age $(\$)(n=3$; means are given \pm SD). RNA-seq: Wald's exact test was used to identify any differentially expressed genes (DEGs) under the $p$-value adjustment $(p<0.05)$ for multiple comparisons with the Benjamini-Hochberg False Discovery Rate (FDR) correction. Values that were significantly different from the E0 culture at the same age (\#); the EA culture at the same age $(\$)(n=3$; means are given $\pm S D)$. 


\subsubsection{HAT Genes}

The RNA-seq data on the expression of the 12 HATs that are encoded in the Arabidopsis genome [80] indicated that SE induction is associated with the upregulation of numerous genes that represent different gene families, including GNAT, MYST, CBP and $T A F_{\text {II }} 250$ (Table S7, Figure 3). Auxin treatment resulted in an increased expression (FC 1.3-5.9) of seven HAT (HAG1/GCN5, HAG2, HAG3, HAG4, HAG5, HAC2 and HAC5) genes (Figure $3 \mathrm{~A}-\mathrm{G}$ ), while three genes, HAG2, HAC2 and HAF2 (Figure 3B,F,I) were upregulated in the TSA-induced culture compared to the E0 culture. Two HATs, HAG2 and HAC2 (Figure $3 \mathrm{~B}, \mathrm{~F}$ ), were upregulated in response to both the EA and ET media. In particular, HAC2 was highly responsive to both treatments and had a 5.9 and 12.6 FC increase in its transcript level in the EA and ET culture, respectively (Figure 3F). In contrast, HAC4 was downregulated in the TSA-induced culture compared to the EA culture (Figure $3 \mathrm{H}$ ). Together, the results imply the activation of different $H A T$ genes in SE induction and the role of auxin and Hac in regulating these genes might be assumed.

A
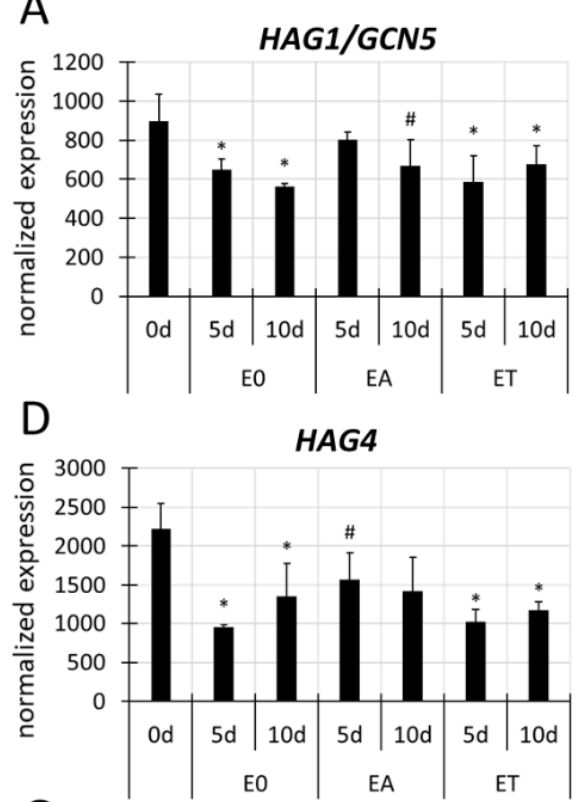

G

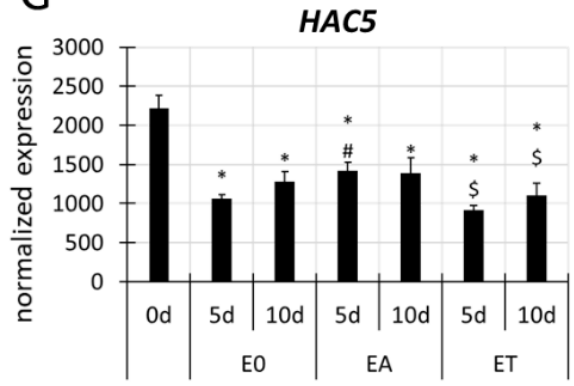

B

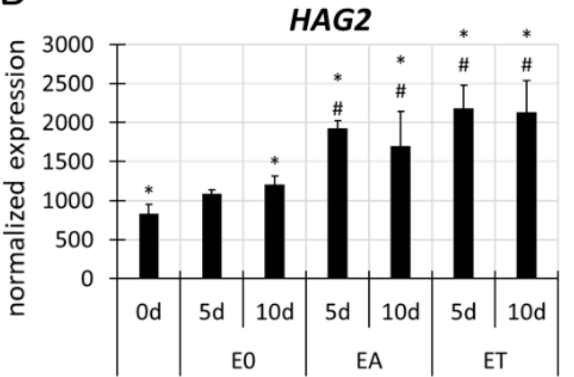

$\mathrm{E}$

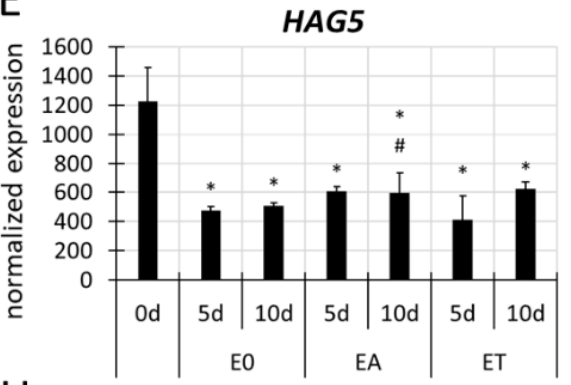

$\mathrm{H}$

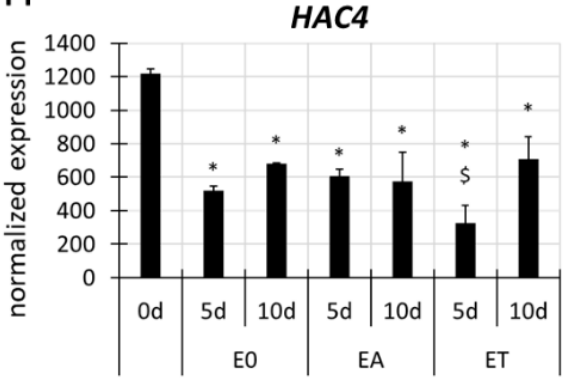

C

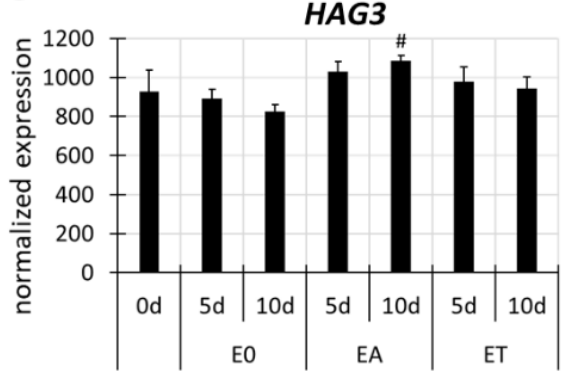

$\mathrm{F}$

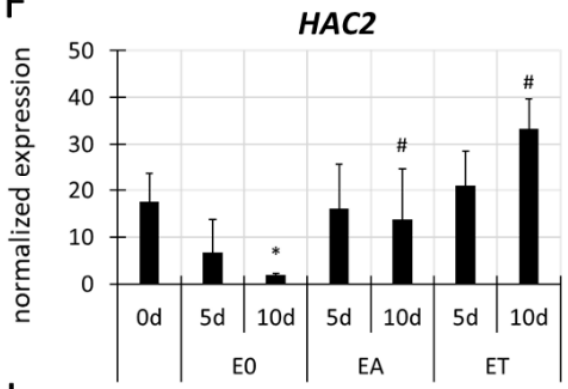

I

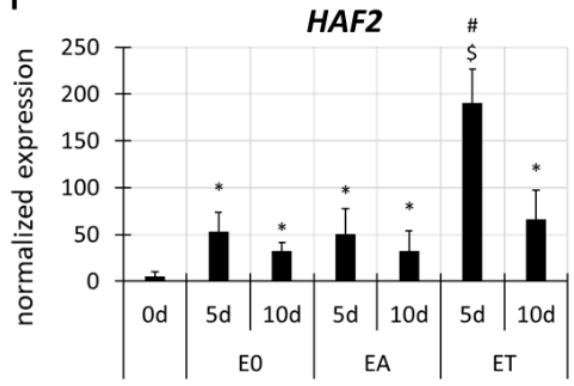

Figure 3. Differential expression of the HAT genes, including HAG1/GCN5 (A), HAG2 (B), HAG3 (C),

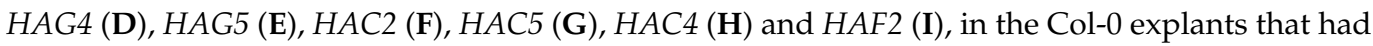
been cultured on the E0, EA and ET media for 0, 5 and 10 days. Graphs represent the data from the RNA-seq analysis. Wald's exact test was used to identify any differentially expressed genes (DEGs) under the $p$-value adjustment $(p<0.05)$ for multiple comparisons with the Benjamini-Hochberg False Discovery Rate (FDR) correction. Values that were significantly different from $0 \mathrm{~d}(*)$; the E0 culture at the same age (\#); the EA culture at the same age $(\$)(n=3$; means \pm SD are given).

Next, in order to identify the specific HATs that are involved in auxin-induced SE, we analysed the embryogenic response of different hat mutants in a standard embryogenic 
culture on an EA medium. The results indicated a defective SE response of six hat mutants (hag2, hac1, hac4, hac5, haf1 and haf2); their explants produced somatic embryos with a distinctly decreased efficiency or productivity in response to the auxin treatment (Figure 4). It is worth noting that the defective SE-response of four mutants, hac1, hac4, hac5 and haf2, was specific to the EA culture because the embryogenic response of these mutants was not impaired on the ET medium (Figure S3). This finding suggests that the function of the relevant HATs, HAC1, 4, 5 and HAF2 genes might be specific to auxin-induced SE.

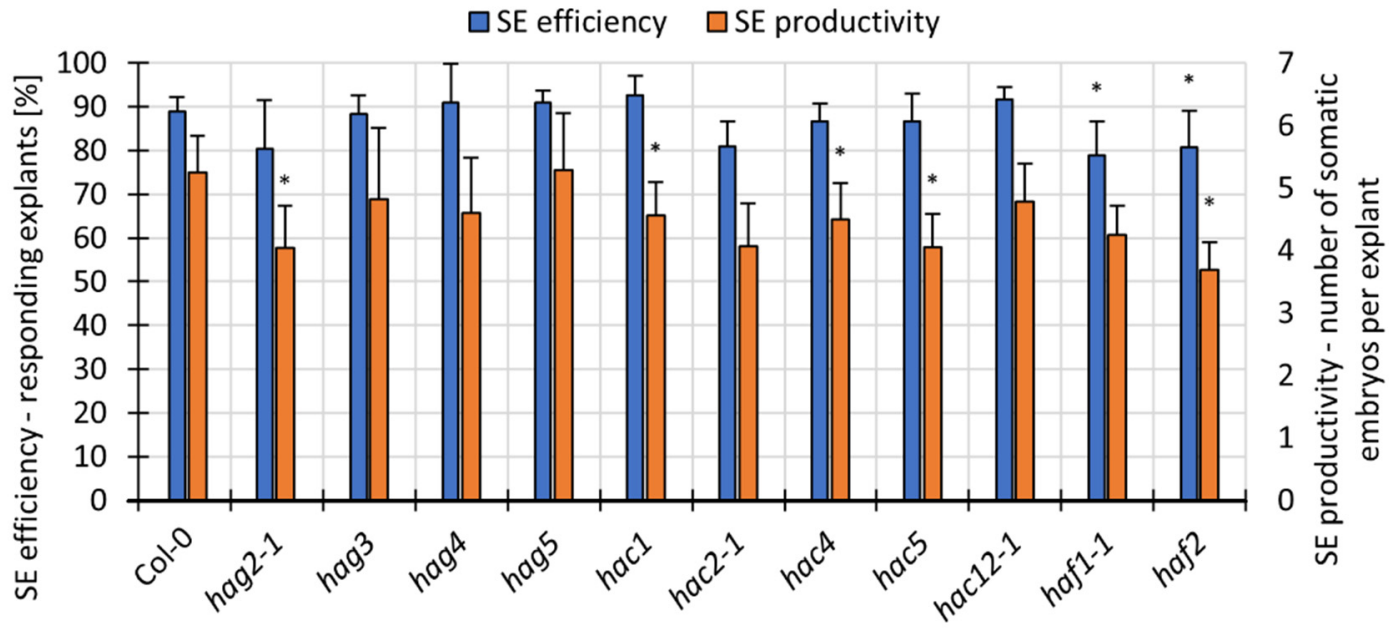

Figure 4. The embryogenic capacity of the hat mutants on the EA medium evaluated in the 21-day-old culture. Values significantly different from the control WT culture (Col-0) are marked with an asterisk ( $\mathrm{n} \geq 4$; means $\pm \mathrm{SD}$ are given) (Student's $t$-test, $p<0.05$ ).

In contrast to the numerous hat mutants with SE-impaired potential, mutations in the HAG1/GCN5 gene resulted in an improved embryogenic response (Figure 5). In response to the EA treatment, the hag1-5 and $g c n 5-1$ mutant explants produced a higher average number of somatic embryos per explant (Figure 5A,B). In addition, the hag1-5 and gcn5-1 explants were also able to induce a somatic embryo on the control E0 medium (Figure 5C,D). Therefore, a negative role of HAG1/GCN5 in auxin-mediated SE might be implied.

To summarise, the results imply a role of the genes encoding different HATs in the embryogenic transition of explant cells. Most of the SE-involved HATs, including HAG2, $H A C 1, H A C 4, H A C 5, H A F 1$ and HAF2, seem to positively contribute to SE induction while HAG1/GCN5 might control this process negatively.

\subsubsection{HDAC Genes}

In Arabidopsis, 18 HDAC genes, which are grouped into three gene families, RPD3/ HDA1, SIR2 and plant-specific HD2, encode the histone deacetylases [80]. The RNAseq data on the embryogenic (EA, ET) vs. control (E0) cultures revealed an increased expression of the majority $(12 / 18)$ of the HDACs in response to the embryogenic treatments (Table S8, Figure 6). Seven SE-upregulated HDACs had an increased expression in the EA and ET cultures, including HDA5, HDA9, HDA19, HDT1, HDT2, HDT3 and SRT1 (Figure 6A,D,G-J,L). Four HDACs had a treatment-specific upregulation, including the HDA15 (Figure 6E) in EA and HDA6, HDA18 and HDT4 (Figure 6B,F,K) in the ET culture. In addition, $H D A 8$ was downregulated in the TSA-induced culture compared to the E0 culture (Figure 6C). Therefore, we assumed that although both the auxin and TSA treatments seemed to positively regulate most of the HDAC genes, the contribution of individual genes to TSA- vs. auxin-induced SE might differ. 
A $\square$ SE efficiency $\square$ SE productivity

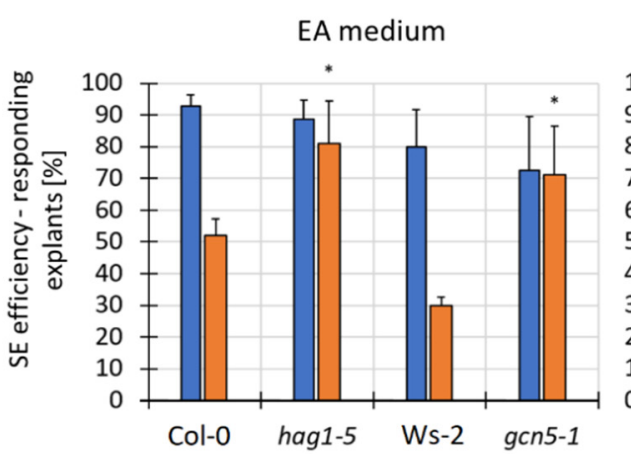

C

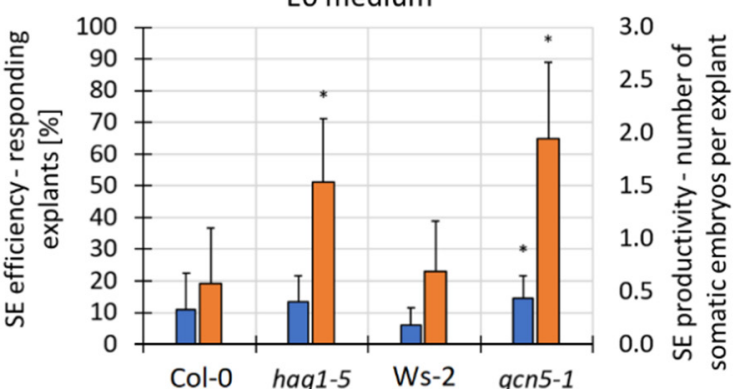

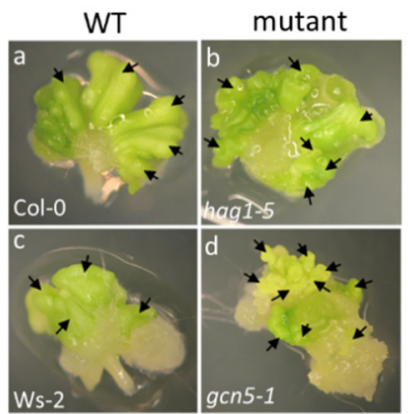

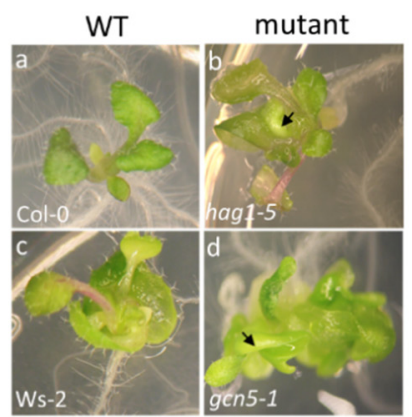

Figure 5. The increased embryogenic capacity of the hag1/gcn 5 mutants in the explants that had been cultured for 21 days on the EA (A,B) and E0 (C,D) medium. Arrows indicate the somatic embryos (B) and embryo-like structures (D). Values significantly different from the control WT culture (Col-0 or Ws-2) are marked with an asterisk $(\mathbf{A}, \mathbf{C})(\mathrm{n} \geq 6$; means $\pm \mathrm{SD}$ are given) (Student's $t$-test, $p<0.05$ ).

Altogether, the results indicated that the substantial upregulation of numerous HDAC genes in SE induction seems to be controlled by auxin and Hac.

To gain further insight into the specific HDACs that are involved in auxin-induced SE, we analysed the $h d a c$ mutants and transgenic RNAi lines in terms of their capacity for an embryogenic response. The analysis indicated seven mutants that had a significantly lower SE productivity, including $h d a 2, h d a 5, h d a 7, h d t 1, h d t 3, h d t 4$ and $s r t 1$ in the EA vs. E0 cultures (Figure 7). In contrast, the HDA19:RNAi explants had an improved embryogenic response, which was manifested by the distinctly higher number of somatic embryos that were produced on the EA medium (Figure 8A,B). Moreover, this line also produced somatic embryos on the control auxin-free E0 medium (Figure $8 \mathrm{C}, \mathrm{D}$ ). The improved embryogenic potential of the HDA19:RNAi culture suggests that there is a negative impact of the HDA19 gene on SE induction.

Altogether, the gene expression profiling and mutant analysis results imply that different HATs and HDACs might positively or negatively contribute to SE induction. Most of the SE-deregulated HATs and HDACs, including HDA2, HDA5, HDA7, HDT1, HDT3, HDT4 and SRT1, might positively control SE induction. In contrast, HAG1/GCN5 and HDA19 seem to negatively regulate SE response.

\subsection{Mutations in HAT and HDACs Affect the Expression of Essential SE-TF Genes}

For further insights into the mechanisms by which HATs and HDACs might contribute to the embryogenic response, we analysed the expression of the $L E C 1, L E C 2$ and $B B M$ genes in the EA-induced explants of the hat (hag1/gcn5) and hdac (hdt1, hdt4, HDA19:RNAi) lines that were significantly affected SE response (Figures 5, 7 and 8). The results indicated substantial changes in the expression level of the SE-TFS in the mutant cultures. The diversity of the gene expression profiles between the genes was indicated and both an upand downregulation of the genes were observed. The silencing of HDA19 affected different SE-TFs differently. A significant downregulation of $B B M$ (FC 0.3-0.6) and upregulation 
(FC 3.5-4.3) of $L E C 1$ and $L E C 2$ were observed in the explants $(0 \mathrm{~d})$ and the SE culture of HDA19:RNAi (Figure 9A). The results suggest that HDA19 might regulate LEC1 and LEC2 negatively while it impacts $B B M$ positively.

A

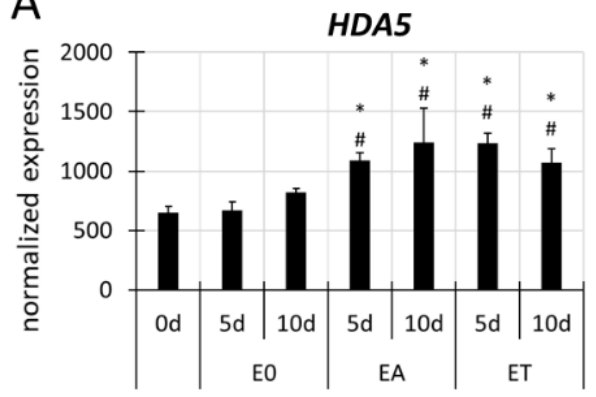

D

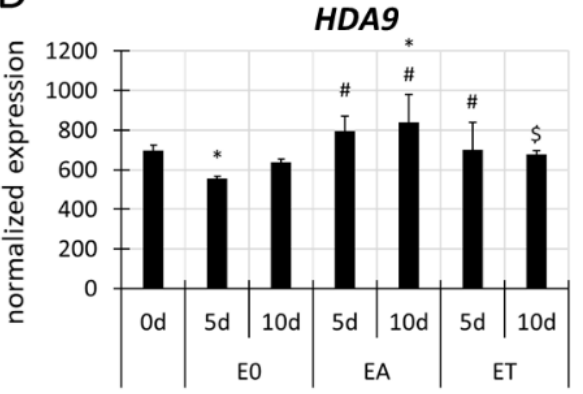

G

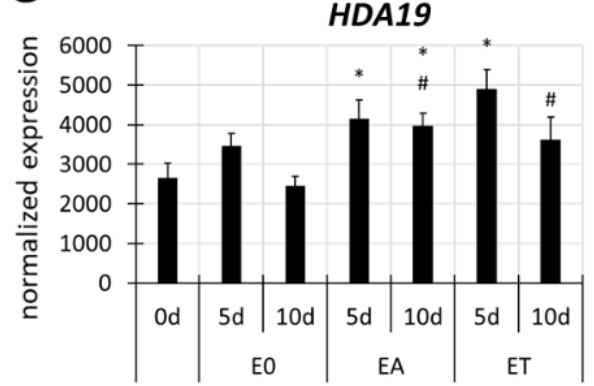

J

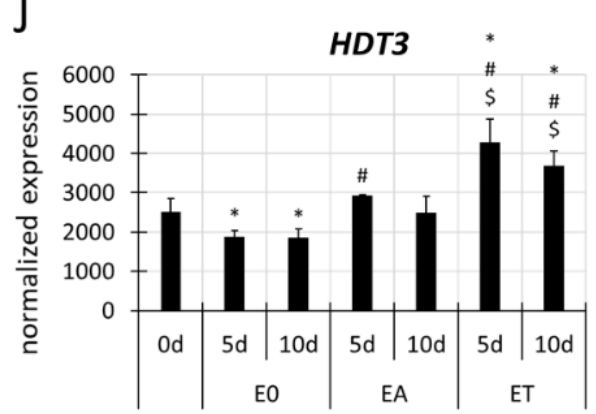

B

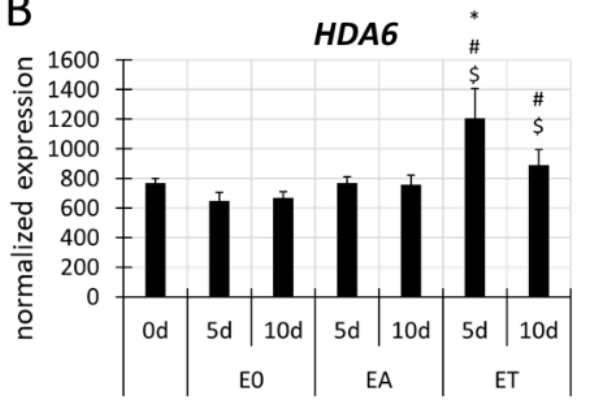

E

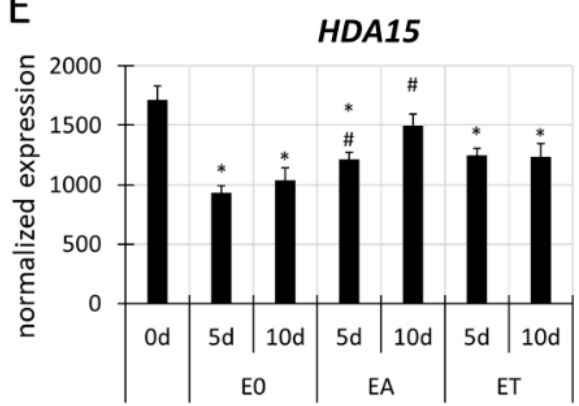

$\mathrm{H}$

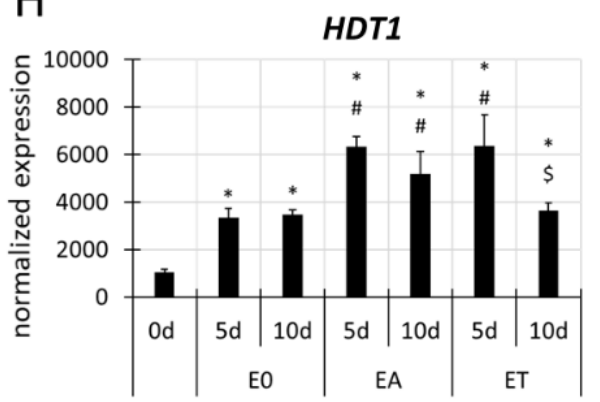

K

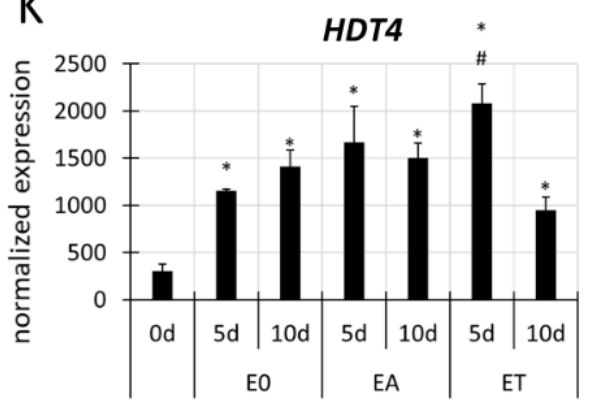

C

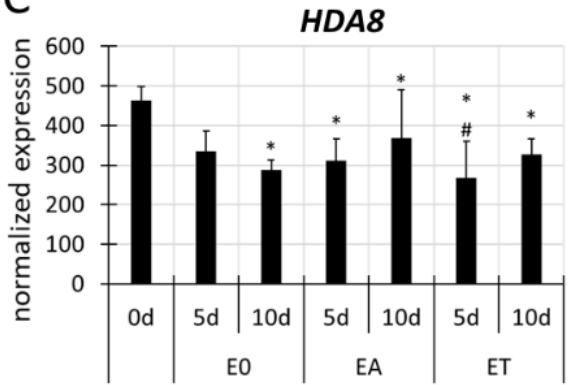

$\mathrm{F}$

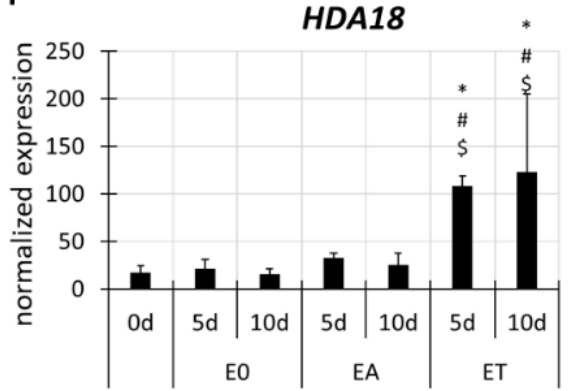

।

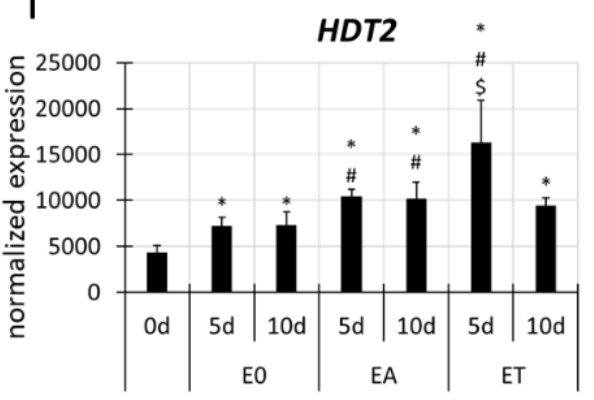

$\mathrm{L}$

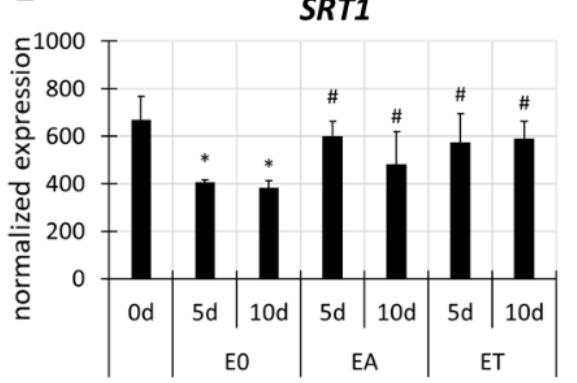

Figure 6. Differential expression of the HDAC genes, including HDA5 (A), HDA6 (B), HDA8 (C),

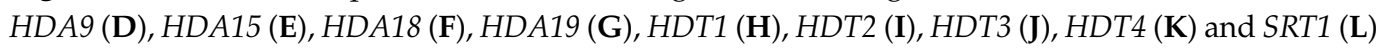
in the Col-0 explants that had been cultured on the E0, EA and ET media for 0, 5 and 10 days. Graphs represent the data from the RNA-seq analysis. Wald's exact test was used to identify any differentially expressed genes (DEGs) under the $p$-value adjustment $(p<0.05)$ for multiple comparisons with the Benjamini-Hochberg False Discovery Rate (FDR) correction. Values that were significantly different from $0 \mathrm{~d}(*)$; the E0 culture at the same age (\#); the EA culture at the same age $(\$)(\mathrm{n}=3$; means $\pm \mathrm{SD}$ are given). 


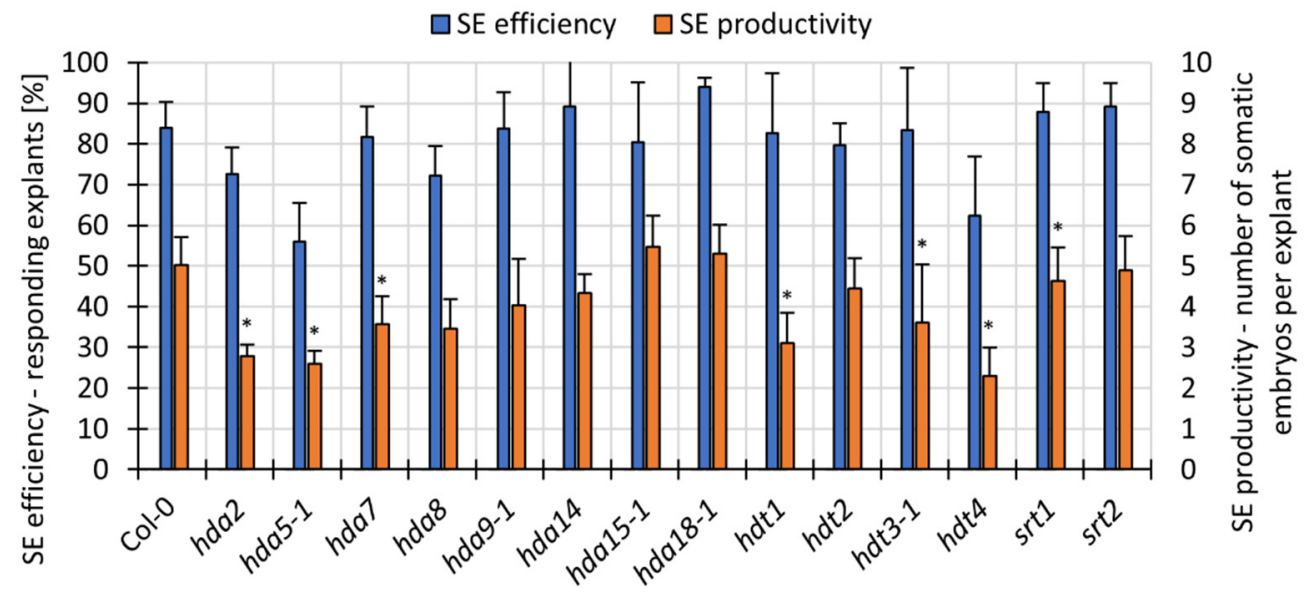

Figure 7. The embryogenic capacity of the hdac mutants on the EA medium evaluated in the 21-dayold culture. Values that were significantly different from the control WT culture (Col-0) are marked with an asterisk ( $\mathrm{n} \geq 4$; means $\pm \mathrm{SD}$ are given) (Student's $t$-test, $p<0.05$ ).

A $\quad \square$ SE efficiency $\square$ SE productivity
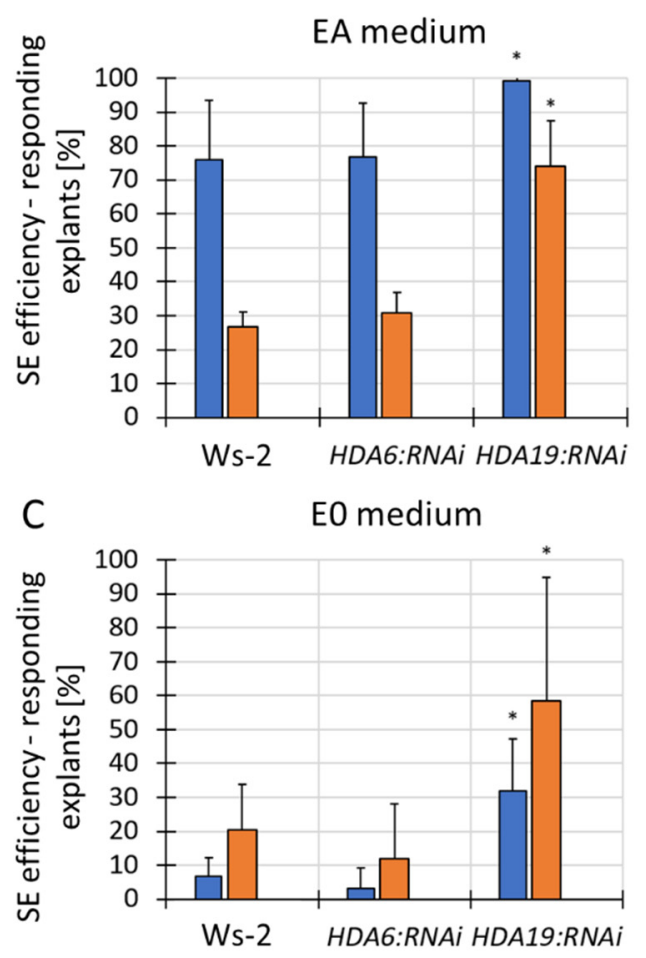

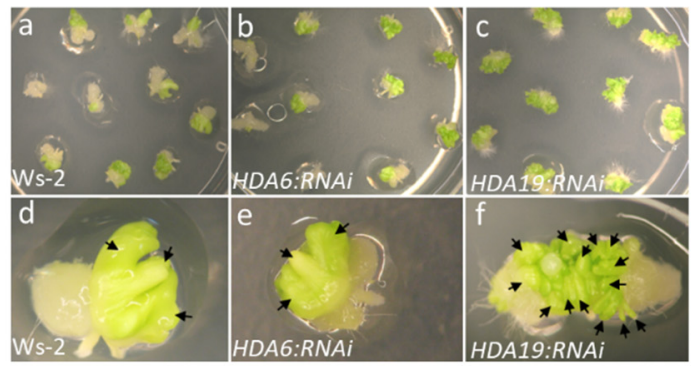

D

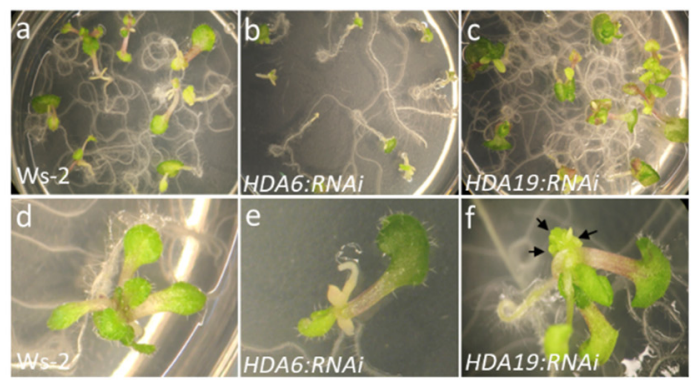

Figure 8. The embryogenic capacity of the HDA6:RNAi and HDA19:RNAi explants that had been cultured on the EA (A,B) and E0 (C,D) media for 21 days. Values that were significantly different from the control WT culture (Ws-2) are marked with an asterisk $(\mathbf{A}, \mathbf{C})(\mathrm{n} \geq 5$; means \pm SD are given) (Student's $t$-test, $p<0.05)$. Arrows indicate the somatic embryos (B: d, e, f) and embryo-like structures (D: f). 
A

SE-TFs in HDA19:RNAi

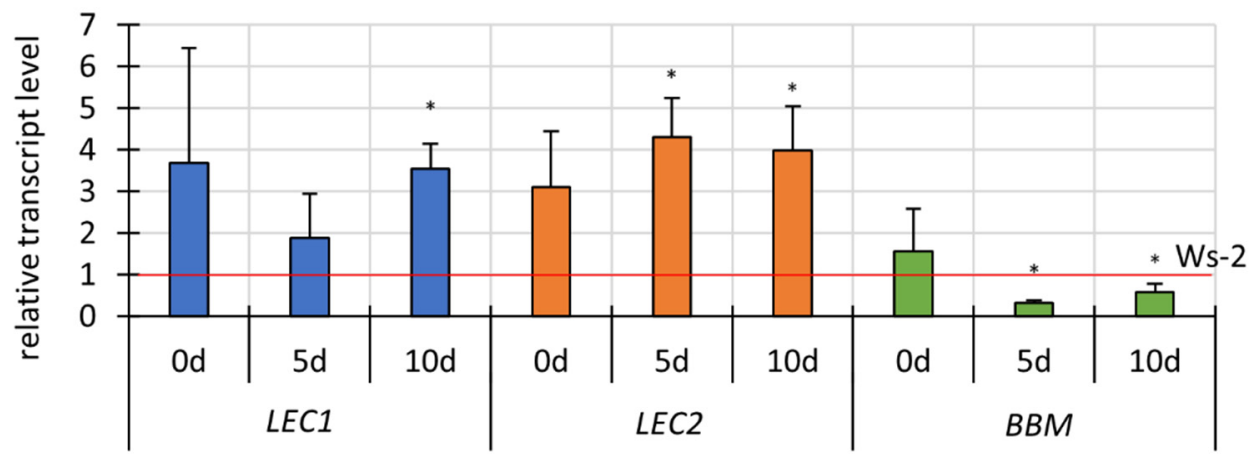

B

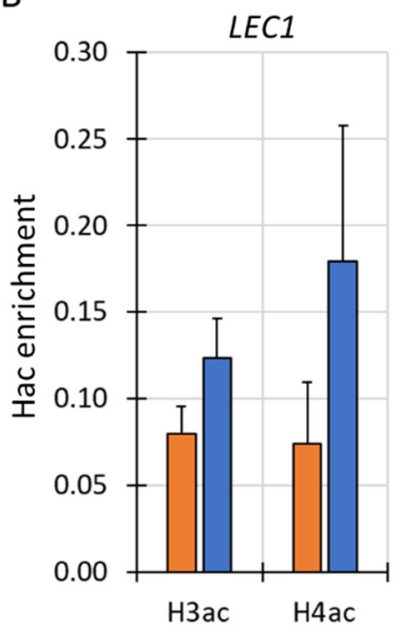

C

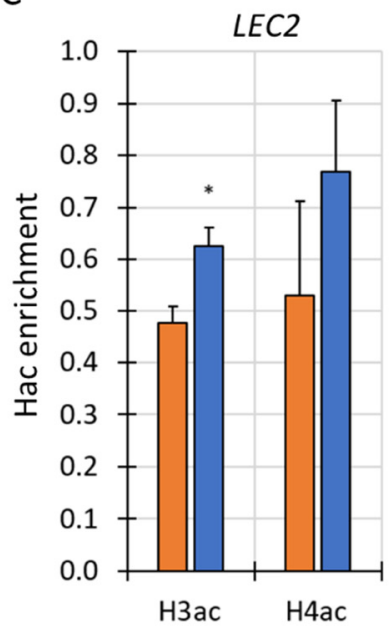

D

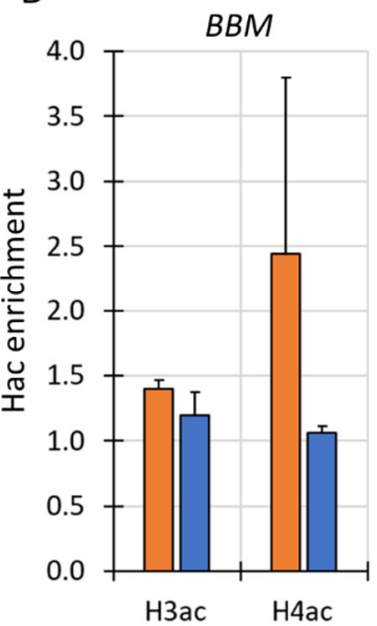

$\square$ Ws-2 $\square$ HDA19:RNAi

Figure 9. The involvement of HDA19 in controlling the LEC1, LEC2 and BBM genes in SE induction. Expression profiles of the SE-TFs in freshly isolated $(0 \mathrm{~d})$ and explants that had been cultured on the EA medium ( 5 and $10 \mathrm{~d}$ ) of the HDA19:RNAi line (A). The relative transcript level was normalised to the internal control (TIN gene) and calibrated to the control WT cultures of Ws-2. Graph represents the data from the RT-qPCR analysis. The H3ac and H4ac levels in the chromatin that is associated with LEC1 (B) LEC2 (C) and BBM (D) in SE. The Hac levels in the chromatin that is bound to the TSS+300 bp gene fragment were evaluated in the HDA19:RNAi and Ws-2 (WT) explants that had been cultured on the EA medium for five days. The Hac enrichment indicated the amount of DNA after ChIP that was normalised to the internal control (ACTIN7). An asterisk indicates values that were significantly different than the ones observed in Ws-2 ( $\mathrm{n}=3$; means $\pm \mathrm{SD}$ are given) (Student's $t$-test, $p<0.05)$.

Gene profiling in the other two $h d a c$ mutants, $h d t 1$ and $h d t 4$, revealed a significantly decreased expression of all three genes, LEC1, LEC2 and BBM (FC 0.02-0.2), in the explants $(0 \mathrm{~d})$ and during SE culture (Figure S4A). The results imply a positive impact of HDT1 and HDT4 on the SE-TFs expression. In contrast, histone acetyltransferase HAG1/GCN5 seems to affect the SE-TF genes differently. The gene expression profiling of the gcn5-1 mutant explants revealed an increased expression level of LEC1 (FC 3.0-5.5) and LEC2 (FC 1.2-3.6) and the downregulation of $B B M(F C$ 0.2-0.7) in the freshly isolated $(0 \mathrm{~d})$ and EA-induced explants (Figure S4B). These results suggest that HAG1/GCN5 might negatively control $L E C 1$ and $L E C 2$ while positively regulating $B B M$ during auxin-induced SE.

Taken together, the results regarding gene profiling in the hat/hdac mutant cultures provide some suggestions that HAT and HDACs by fine-tuning the TF genes, including 
$L E C 1, L E C 2$ and $B B M$, might control the embryogenic response. However, the diverse expression profiles of the SE-TFs in the hat and hdac mutants imply that further analyses are required to reveal the complex and gene-specific mechanisms by which different HAT/HDACs might affect the SE-TFs during embryogenic induction.

\subsection{HDA19 Might Negatively Control LEC2 in SE Induction via Histone Deacetylation}

The improved embryogenic response (Figure 8), together with modulated TF gene expression in the HDA19:RNAi culture (Figure 9A), motivated us to investigate whether HDA19 might control the SE-TFs via histone acetylation. To answer this question, we analysed the Hac level in the chromatin that is associated with LEC1, LEC2 and BBM in the HDA19:RNAi and WT (Ws-2) explants that had been cultured on the EA medium (Figure 9B-D). ChIP-qPCR indicated a significant H3ac enrichment in the chromatin that was associated with LEC2 in the HDA19:RNAi culture (Figure 9C). This result, together with the increased LEC2 transcription in the HDA19:RNAi culture (Figure 9A), supports the assumption of a role of HDA19 in the negative control of LEC2 in SE induction.

In contrast to $L E C 2$, the Hac level in the chromatin that is associated with the TSS+300 bp fragment of the LEC1 and BBM genes was not significantly affected in the HDA19:RNA culture (Figure 9B,D). The results indicated a lack of any Hac changes in the chromatin that is bound to the TSS $+300 \mathrm{bp}$ regions of the LEC1 and BBM genes in response to the silencing of HDA19. The mechanism of the HDA19-mediated control of these genes during auxin-induced embryogenic response requires further analysis.

\section{Discussion}

\subsection{Changes in Histone Acetylation Accompany SE Induction}

The developmental reprogramming of somatic cells in animals and plants is associated with extensive changes in the cell transcriptome that is controlled by the compactness of chromatin $[10,81,82]$. Accordingly, histone acetylation-mediated chromatin accessibility has been postulated to control genes in the in vitro-induced plant development, including the embryogenic transition of the somatic cells that accompany SE induction $[16,83]$.

These results indicated distinct differences in the Hac abundance in the embryogenic vs. non-embryogenic cultures of Arabidopsis (Figure 1). A substantial decrease in the global H3 acetylation level was specific to the non-embryogenic control culture. Stress factors have been widely documented as distinctly affecting Hac in plants $[84,85]$. Therefore, we assumed that the stress that is imposed by in vitro-culture conditions would negatively affect Hac in the explant tissue. In support of this, the SE-induced explants had a significantly higher level of global H3ac than the non-embryogenic culture. Hence, we hypothesised that TSA and auxin seem to counteract the in vitro-culture/stress-induced histone deacetylation, thereby increasing Hac and inducing SE in the treated explants.

In line with the increased Hac level in the ET culture, histone hyperacetylation after TSA treatment has been reported in different plant developmental processes in vivo [86] and in vitro $[28,87]$. The TSA-increased Hac is believed to result from the inhibition of the HDACs of the RPD3/HDA1 and HD2-type families, which are the targets of TSA [88,89]. Similar to TSA, a positive effect of auxin treatment, including 2,4-D, on the Hac level in in vitro-cultured cells and tissue has also been reported [25,90,91]. Consistent with the auxin-induced changes in the Hac level, the involvement of Hac in the auxin-induced transcriptional regulation of genes has also been demonstrated [92-94]. In this mechanism, auxin affects the recruitment of HDACs and HATs to the transcriptional complexes that differentially acetylate histones at the target loci [95].

The immunohistochemical analysis of the Hac pattern in the IZE explants showed that the meristematic zones (SAM and RAM) and vascular tissue in the hypocotyls of the zygotic embryos, both those that were freshly isolated and those that were in vitro cultured had the most intense Hac signals. Similarly, the Hac signals were co-localised with the meristematic regions in the zygotic embryos of Hordeum vulgare and Brachypodium distachyon [66,96]. Enhanced H4ac signals have also been reported in the meristematic 
regions of microspore-derived $B$. napus embryos as well as the vegetative and floral buds of plants $[31,97,98]$. Different cell types, including meristematic cells, might exhibit specific patterns of epigenetic modifications as was indicated for DNA methylation in the RAM and histone methylation in the SAM of Arabidopsis [99,100]. Whether the higher accumulation of Hac might be attributed to cells with a meristematic identity remains to be verified.

It is worth noting that the pattern of the Hac signals in the explants seems to coincide with the IAA accumulation regions in a zygotic embryo that involve the meristematic (SAM, RAM) and vascular tissues [101,102]. However, less intensive, dispersed patches of Hac signals were also found in the IZE cotyledons that are directly involved in the development of the somatic embryos [79]. Moreover, auxin biosynthesis followed by an increase in IAA in SE-involved explant tissue has also been postulated $[45,56,103]$. In support of the postulated convergence between Hac and the IAA accumulation, the role of Hac in auxin biosynthesis, including the regulation of the YUCCA genes that control IAA biosynthesis in SE, has been indicated $[45,104,105]$. Thus, we hypothesised that the Hac signals in the cotyledons, similar to the meristematic and vascular tissues, might co-localise with the areas with an increased IAA content that are engaged in somatic embryo development. An analysis of the Hac vs. IAA accumulation in the distinct SE-involved sites of the cotyledons might verify the functional relevance of Hac and auxin in the embryogenic reprogramming of explant cells.

The immunohistochemical assay revealed global changes in the spatio-temporal Hac pattern in the in vitro-cultured explants, both the control and SE-induced explants. Hac signals were detected in different explant parts and they were not specifically co-localised with the SE-involved cotyledons. Moreover, the quantification of the H3ac signals in the cotyledons exhibited no significant differences between the embryogenic (EA and ET) and control (E0) cultures. A possible explanation for this result provided a recent report on rather limited heterochromatin decondensation in the SE-involved cotyledon cells in response to auxin [106]. Together, these results imply that discrete and cell-specific changes in Hac might accompany SE induction. That implies that revealing the discrete Hac-related changes in chromatin of SE-induced explants might require an analysis of specific auxin-responsive protodermal cells at the adaxial side of cotyledons [79].

\subsection{Hac Controls LEC1, LEC2 and BBM during TSA-Induced Embryogenic Reprogramming}

The results regarding the global changes in Hac abundance in the SE-induced explants implied the role of Hac in the embryogenic reprogramming of somatic cells. To reveal the regulatory mechanism by which Hac controls SE, we analysed the changes in the Hac in the chromatin that is associated with the TF genes that have regulatory functions in embryogenic induction. The Hac-regulated candidates involved the TF genes with a TSAaffected expression, including LEC1, LEC2, FUS3, BBM, AGL15 and MYB118 [37,38,87]. The results of the ChIP-qPCR indicated that the increased transcription of LEC1, LEC2, FUS3 and MYB118 in the TSA-induced SE was associated with an accumulation of H3ac and $\mathrm{H} 4 \mathrm{ac}$ in the gene-bound chromatin (Figure 2). The analysed H3 (H3K9ac and H3K14ac) and $\mathrm{H} 4$ (H4K5ac, H4K8ac, H4K12ac and H4K16ac) lysine residues activate gene transcription in plants and they are frequently enriched in the TSS regions of genes [107]. The reported role of $\mathrm{H} 3 / \mathrm{H} 4 \mathrm{ac}$ marks in the regulation of different genes [4,108] together with a significant increase in the $\mathrm{H} 3$ and $\mathrm{H} 4$ acetylation and transcript abundance of the LEC1, LEC2, and FUS3 imply the role of Hac in the transcriptional control of these genes during TSA-induced SE (Figure 2). Congruently, the role of Hac in regulating LEC1 and LEC2 in Arabidopsis during seedling development was reported [57-59]. The results of the ChIP-qPCR indicated that in contrast to TSA, the explants that had been treated with auxin had no significant modulation of the H3ac and H4ac levels in the analysed chromatin fragments that were bound to the SE-TFs. The results suggest that different gene regions and/or lysine marks in the SE-TFs-bound chromatin might be targeted by auxin and TSA in the treated explants.

Consistent with this assumption, the chromatin that was bound to TSS gene regions other than those analysed, including the promoters of the SE-TFs might undergo a dif- 
ferential Hac in response to auxin [94]. The lysines that are targeted by auxin-mediated histone acetylation include the H3K27 mark [93,94] which was not analysed in the present study. Thus, an analysis of other lysine marks, predominantly H3K27ac, in the different regions of the SE-TFS might be important in studies on the Hac-related mechanisms that control the genes during auxin-induced SE. The present results show that a complex and to date only partially recognised mechanism of the auxin-controlled Hac [95] might be different from the one that is involved in TSA-induced Hac in which the inhibition of the HDACs promotes Hac [85]. Further analysis is required to reveal the common and treatment-specific elements of the auxin- vs. TSA-triggered gene regulation via Hac.

\subsection{Numerous HATs and HDACs Control SE Induction}

In SE induction, the changes in Hac result from the activity of the antagonistically acting enzymes, HATs and HDACs, that play a role in regulating the genes in plant development $[109,110]$. In support of the involvement of HAT/HDACs in SE induction, a differential expression of the HAT/HDAC genes and the modulated activity of the encoded enzymes have been reported in the embryogenic cultures of different plants, including Arabidopsis [30,38,111]. Similarly, we revealed the deregulation of several HAT (HAG1/GCN5, HAG2, HAG3, HAG4, HAG5, HAC2, HAC4, HAC5 and HAF2) and HDAC (HDA5, HDA6, HDA8, HDA9, HDA15, HDA18, HDA19, HDT1, HDT2, HDT3, HDT4 and SRT1) genes in the 2,4-D- and TSA-induced embryogenic explants (Figures 3 and 6). The differential expression of HATs and HDACs in response to the HDAC-inhibitors and auxin treatment has also been indicated by others, which suggests that Hac and auxin play a role in the transcriptional control of these genes [36,112-114]. Accordingly, Hac has been indicated in the chromatin that is associated with the HAT/HDACs genes (PlantPan 3.0, [115]). In support of an auxin-responsive expression, most $H A T$ and $H D A C$ promoters carry the auxin-response elements (AuxREs). In line with this finding, the $H A T / H D A C$ genes were co-expressed with the ARFs (AUXIN RESPONSE FACTOR) which are core regulators in auxin signalling and make a fundamental contribution to embryogenic induction (Tables S9 and S10; PlantPan 3.0, [115]) [116].

The impaired embryogenic response of numerous hat (hag2, hac1, hac4, hac5, haf1 and haf2) and $h d a c(h d a 2, h d a 5, h d a 7, h d t 1, h d t 3, h d t 4$ and srt1) mutants suggests that the relevant HAT/HDACs positively control the SE response (Figures 4 and 7). Within them, the function of the HDT1, HDT2, HDT3, HDT4 and HDA7 of HDACs and HAC1 of the HATs in embryogenic development both in vivo and in vitro has been postulated [29,117-119]. The SE-related functions of other HDACs (HDA5, HDA9 and SRT1) and HATs (HAG4, $H A G 5)$ might also be assumed, given the contribution of these genes to plant flowering and the ethylene responses of transcriptomic similarity to SE induction [63,120-123].

In contrast to the majority of hat/hdac mutants, the gcn5-1/hag1-5 mutants and the HDA19:RNAi transgenic line had an improved embryogenic potential, thus suggesting that the relevant genes, HAG1/GCN5 and HDA19, negatively control SE induction (Figures 5 and 8). Similarly, the silencing of HDA19 resulted in the formation of somatic embryo-like structures on the germinating seedlings [37]. In line with their assumed roles in SE induction, HAG1/GCN5 and HDA19 control various developmental processes and stress responses in plants, including cell differentiation and hormone responses [8,124,125].

We provide experimental evidence that HDA19 might control the expression of TFs during SE, including negative $L E C 1$ and $L E C 2$ regulation and positive impact on $B B M$ (Figure 9A). Similarly, the HDA19-mediated negative control of LEC2 has also been indicated in the seedlings of Arabidopsis [57]. In addition to LEC2, HDA19 has been postulated to control LEC1 in seedling development, although ambiguous results have also been reported on HDA19 binding to LEC1 [57,126]. The ChIP results indicated that the increase in the LEC2 expression in the SE-induced explants was associated with an H3ac accumulation in the gene-bound chromatin fragment (Figure 9C).

Our Hac analyses involved a chromatin fragment that was bound to the TSS+300 bp gene region with an indicated role in the Hac-mediated control of genes [4,5]. A lack of Hac 
changes in the TSS+300 bp fragment of $L E C 1$ and $B B M$ does not exclude other gene regions, including the promoter that is involved in HDA19-controlled Hac [57]. Another scenario for the HDA19-mediated gene regulation might involve the indirect effect of HDA19 on the $L E C 1$ and BBM expression, possibly via LEC2. In support of this hypothesis, the complex direct and indirect regulatory interactions between LEC2 and the other TFs, including LEC1 and BBM, in SE induction have been documented [116].

In order to control plant development, HAG1/GCN5 and HDA19 might affect the versatile gene regulatory pathways and many transcripts were deregulated in the gcn5 and hda19 mutants $[127,128]$. The results of the TFs profiling in the gcn5-1 culture showed a deregulation of the $L E C 1, L E C 2$ and $B B M$ expression during SE (Figure S4B). Both a positive and negative regulation of gene expression via HAG1/GCN5 has been reported and its targets also involve the genes that are involved in SE $[26,116,129]$. Because many transcripts were deregulated in the $g c n 5$ and thousands of gene promotors might be HAG1/GCN5-targeted [130], the correct interpretation of the results regarding the deregulation of the genes in the gcn5-1 culture (Figure S4B) in terms of the regulatory relationship between HAG1/GCN5 and TFs in SE, requires further analysis. In particular, the role of HAG1/GCN5 in the early stage of SE induction (before the fifth day) might be important for identifying how HAG1/GCN5 controls SE. In support of this postulate is the effect of a specific HAG1/GCN5 inhibitor, MB-3 [131], on the early embryogenic response of the explants (JM and MDG unpublished results). The results showed that the MB-3-induced inhibition of HAG1/GCN5 that occurred at the early stage of the culture severely impaired the SE response of the explants. Thus, a complex and SE stage-specific effect of HAG1/GCN5 on the target gene expression might be assumed, including a cooperative activity with other HAT/HDACs such as HDA19 [124,132]. Moreover, the Hac-mediated regulatory network that controls the TFs during SE might also involve HDT1 and HDT4 (Figure S4A). In support of this, the role of HDT1 in regulating BBM during callus formation and somatic cell reprogramming has also been postulated [25].

\section{Conclusions}

Consistent with the central role of auxin in SE induction, a model for the Hac-mediated control of the auxin-responsive genes, including the TFs that are essential in SE induction, is postulated (Figure 10). In support of the relevance of the model to SE-TFs, AuxRE and GRE elements were identified in the promoters of $L E C 1, L E C 2$ and BBM (PlantPan 3.0, [115]). Following the model, in the absence of auxin, the HDA19-TPL repressive complex binds the AuxRE elements and downregulates the target auxin-responsive genes via interactions with Aux/IAA and the ARFs (Figure 10A) [133-135]. In turn, an accumulation of auxin results in the degradation of Aux/IAA, the release of the HDA19-TPL repressive complex and the recruitment of the SAGA co-activator complex with HAG1/GCN5 to the GRE motifs. As a result, the histones are acetylated and the transcription of the auxin-responsive gene is activated (Figure 10B) $[93,136]$. The auxin-dependent function of HDA19 in controlling the SE-involved TFs is postulated (Figure 10C).

Further progress in revealing the complex epigenome and transcriptome interactions during SE requires the regulatory proteins that recruit HAT/HDACs to the target loci to be identified, including HAG1/GCN5 and HDA19. The candidates involve AGL15, which has complex regulatory interactions with LECs and BBM during SE [39]. By cooperating with the TOPLESS co-repressors, AGL15 might enrol HDA6 and HDA19 into the transcriptional complexes in order to repress the target genes in plant development, including during SE $[61,137]$. 

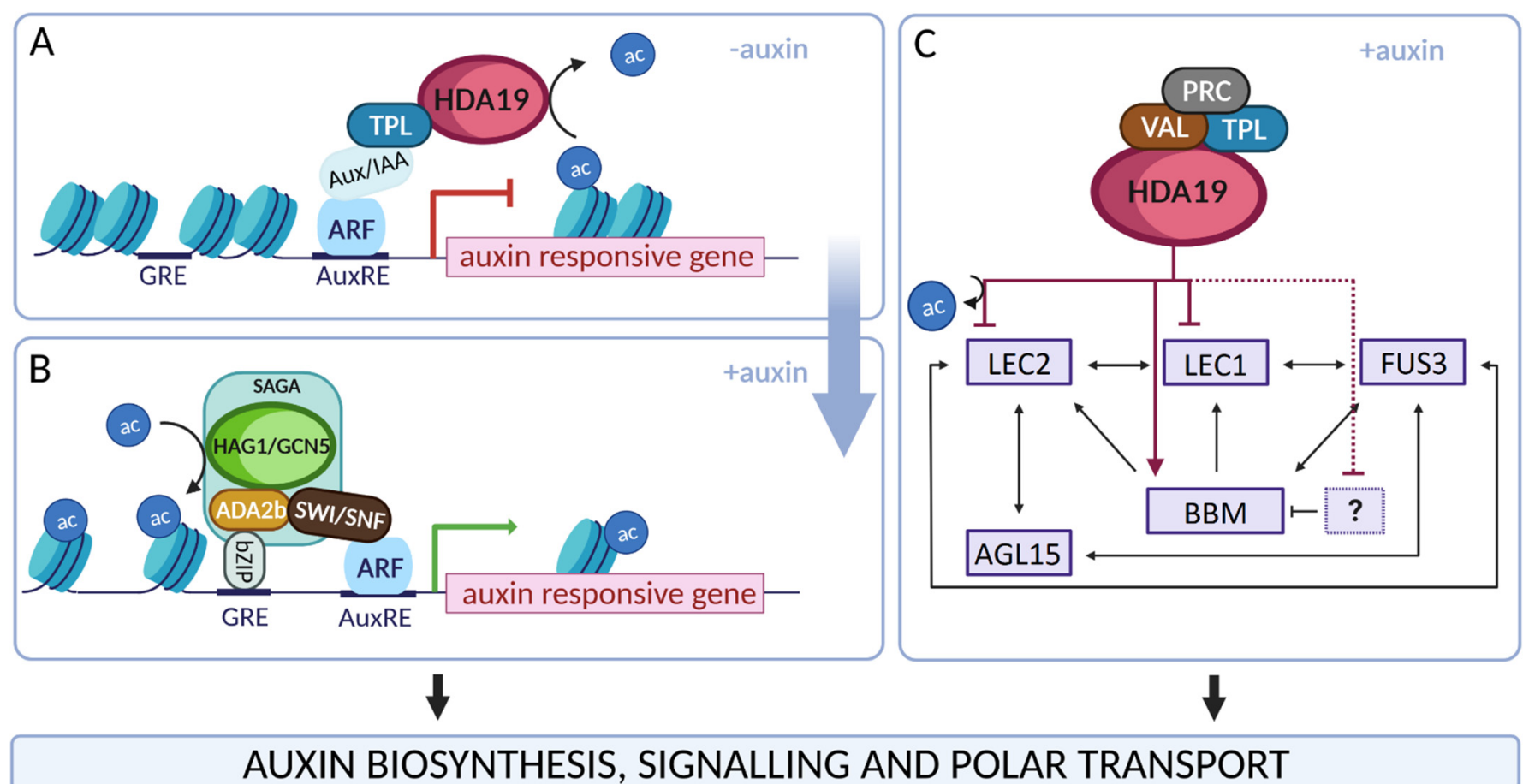

$\downarrow$

AUXIN BIOSYNTHESIS, SIGNALLING AND POLAR TRANSPORT

\section{INDUCTION OF SOMATIC EMBRYOGENESIS}

Figure 10. A model of the Hac-mediated control of auxin-responsive genes, including master regulators of SE induction. To regulate the auxin-responsive genes, histone acetyltransferases and histone deacetylases such as HDA19 (A) and HAG1/GCN5 (B) are assumed to cooperate with the other regulatory proteins of the transcriptional complexes. HDA19 contribute to SE induction by controlling the TFs encoding genes that have a master regulatory function during SE (C). acacetyl group; ADA2b-adapter protein; AGL15-AGAMOUS-LIKE 15; ARF-AUXIN RESPONSE FACTOR; Aux/IAA-Auxin/INDOLE-3-ACETIC ACID; AuxRE-Auxin RESPONSE ELEMENT; BBM-BABY BOOM; bZIP—bZIP-RELATED BASIC LEUCINE ZIPPER; FUS3-FUSCA3; GRE—GBOX RELATED ELEMENT; HAG1/GCN5-HISTONE ACETYLTRANSFERASE OF THE GNAT FAMILY 1/GENERAL CONTROL NON-REPRESSED PROTEIN 5; HDA19-HISTONE DEACETYLASE 19; LEC1;2-LEAFY COTYLEDON 1; 2; PRC—POLYCOMB REPRESSIVE COMPLEX; SAGASpt/Ada/GCN5-ACETYLTRANSFERASE; SWI/SNF-SWITCH/SUCROSE NON-FERMENTING; TPL-TOPLESS; VAL_-VIVIPAROUS1/ABI3-LIKE. Regulatory interactions that require further experimental validation are marked with a dashed line. The schemata was created using BioRender.com.

Supplementary Materials: The following are available online at https://www.mdpi.com/article/10 .3390/ cells11050863/s1, Table S1: The hat mutants used in the study, Table S2: The hdac mutants and RNAi transgenic lines used in the study, Table S3: Summary of the culture combinations and methods used in the study, Table S4: ChIP-qPCR analysis: sequence of the gene-specific primers, size of the amplicons and localisation of the analysed gene regions, Table S5: The gene-specific primers used for the RT-qPCR, Table S6: Comparison of the mean Alexa 488 and DAPI fluorescence intensity in the longitudinal sections across cotyledons of the Col-0 explants that had been cultured on the E0, EA and ET media for 0, 5 and 10 days, Table S7: The HAT gene expression patterns in the Col-0 explants that had been cultured on the E0, EA and ET media for 5 and 10 days, Table S8: The HDAC gene expression patterns in the Col-0 explants that had been cultured on the E0, EA and ET media for 5 and 10 days, Table S9: The promoter and co-expression analysis of the HAT genes, Table S10: The promoter and co-expression analysis of the HDAC genes, Figure S1: The immunodetected spatio-temporal pattern of H3ac in the cotyledons of the Col-0 explants, Figure S2: The H3ac and H4ac levels and expression profiles of BBM, AGL15 and WUS in the Col-0 explants that had been cultured on the E0, EA and ET media for 5 and 10 days, Figure S3: The embryogenic capacity of the hat mutants on the 
ET medium evaluated in the 21-day-old culture, Figure S4: The expression profiles of the SE-TFs in the $h d t 1, h d t 4$ and $g c n 5-1$ mutants in the freshly isolated $(0 \mathrm{~d})$ and explants that had been cultured on the EA medium (5 and $10 \mathrm{~d}$ ).

Author Contributions: J.M., B.W. and M.D.G. conceived and designed the experiments. J.M. and M.D.G. analysed the data and wrote the manuscript. J.M. performed the ELISA, immunohistochemistry, ChIP-qPCR, RT-qPCR experiments and mutant analysis; A.B. performed the imaging using a confocal system and fluorescence intensity measurements. J.M., B.W., K.N. and A.M.W. prepared the material for the ELISA, ChIP and RNA-seq analyses. K.C., B.W., K.N. and A.M.W. prepared the libraries for RNA-seq. K.C. and M.K. performed the RNA sequencing. K.C., B.W. and J.M. analysed the RNA-seq data. All authors have read and agreed to the published version of the manuscript.

Funding: This work was supported by a research grant from the National Science Centre in Poland (OPUS13 2017/25/B/NZ1/01615).

Data Availability Statement: Not applicable.

Acknowledgments: We are grateful to Kim Boutilier (Bioscience, Wageningen University and Research, Wageningen, Netherlands), Konstantinos Vlachonasios (School of Biology, Aristotle University of Thessaloniki, Thessaloniki, Greece) and Keqiang Wu (Institute of Plant Biology, National Taiwan University, Taipei, Taiwan) for providing the plant material and Agnieszka Babczyńska (Faculty of Natural Sciences, University of Silesia in Katowice) for her technical advice and support in using the Tecan Infinite M200 Microplate reader.

Conflicts of Interest: The authors declare no conflict of interest. The funders had no role in the design of the study; in the collection, analyses or interpretation of data; in the writing of the manuscript or in the decision to publish the results.

\section{References}

1. Klemm, S.L.; Shipony, Z.; Greenleaf, W.J. Chromatin accessibility and the regulatory epigenome. Nat. Rev. Genet. 2019, 20, 207-220. [CrossRef] [PubMed]

2. Zentner, G.E.; Henikoff, S. Regulation of nucleosome dynamics by histone modifications. Nat. Struct. Mol. Biol. 2013, 20, 259-266. [CrossRef] [PubMed]

3. Verdin, E.; Ott, M. 50 years of protein acetylation: From gene regulation to epigenetics, metabolism and beyond. Nat. Rev. Mol. Cell. Biol. 2015, 16, 258-264. [CrossRef]

4. Lu, L.; Chen, X.; Sanders, D.; Qian, S.; Zhong, X. High-resolution mapping of H4K16 and H3K23 acetylation reveals conserved and unique distribution patterns in Arabidopsis and rice. Epigenetics 2015, 10, 1044-1053. [CrossRef]

5. Wang, L.; Zhang, F.; Rode, S.; Chin, K.K.; Ko, E.E.; Kim, J.; Iyer, V.R.; Qiao, H. Ethylene induces combinatorial effects of histone $\mathrm{H} 3$ acetylation in gene expression in Arabidopsis. BMC Genom. 2017, 18, 538. [CrossRef] [PubMed]

6. Lee, K.K.; Workman, J.L. Histone acetyltransferase complexes: One size doesn't fit all. Nat. Rev. Mol. Cell. Biol. 2007, 8, 284-295. [CrossRef]

7. Park, S.Y.; Kim, J.S. A short guide to histone deacetylases including recent progress on class II enzymes. Exp. Mol. Med. 2020, 52, 204-212. [CrossRef]

8. Kumar, V.; Thakur, J.K.; Prasad, M. Histone acetylation dynamics regulating plant development and stress responses. Cell. Mol. Life Sci. 2021, 78, 4467-4486. [CrossRef]

9. Narita, T.; Weinert, B.T.; Choudhary, C. Functions and mechanisms of non-histone protein acetylation. Nat. Rev. Mol. Cell. Biol. 2019, 20, 156-174. [CrossRef]

10. Wang, F.X.; Shang, G.D.; Wu, L.Y.; Xu, Z.G.; Zhao, X.Y.; Wang, J.W. Chromatin accessibility dynamics and a hierarchical transcriptional regulatory network structure for plant somatic embryogenesis. Dev. Cell. 2020, 54, 742-757 e748. [CrossRef]

11. Kinoshita, M.; Barber, M.; Mansfield, W.; Cui, Y.; Spindlow, D.; Stirparo, G.G.; Dietmann, S.; Nichols, J.; Smith, A. Capture of mouse and human stem cells with features of formative pluripotency. Cell Stem Cell 2021, 28, 453-471 e458. [CrossRef] [PubMed]

12. Chen, T.; Dent, S.Y. Chromatin modifiers and remodellers: Regulators of cellular differentiation. Nat. Rev. Genet. 2014, 15, 93-106. [CrossRef] [PubMed]

13. Ikeuchi, M.; Favero, D.S.; Sakamoto, Y.; Iwase, A.; Coleman, D.; Rymen, B.; Sugimoto, K. Molecular mechanisms of plant regeneration. Annu. Rev. Plant Biol. 2019, 70, 377-406. [CrossRef] [PubMed]

14. Loyola-Vargas, V.M.; De-la-Peña, C.; Galaz-Avalos, R.; Quiroz-Figueroa, F.R. Plant tissue culture. In Molecular Biomethods Handbook, 2nd ed.; Walker, J.M., Rapley, R., Eds.; Humana Press: Totowa, NJ, USA, 2008; pp. 875-904.

15. Birnbaum, K.D.; Roudier, F. Epigenetic memory and cell fate reprogramming in plants. Regeneration 2017, 4, 15-20. [CrossRef]

16. Wójcikowska, B.; Wójcik, A.M.; Gaj, M.D. Epigenetic regulation of auxin-induced somatic embryogenesis in plants. Int. J. Mol. Sci. 2020, 21, 2307. [CrossRef] 
17. Osorio-Montalvo, P.; Saenz-Carbonell, L.; De-la-Pena, C. 5-azacytidine: A promoter of epigenetic changes in the quest to improve plant somatic embryogenesis. Int. J. Mol. Sci. 2018, 19, 3182. [CrossRef]

18. Chakrabarty, D.; Yu, K.W.; Paek, K.Y. Detection of DNA methylation changes during somatic embryogenesis of Siberian ginseng (Eleuterococcus senticosus). Plant Sci. 2003, 165, 61-68. [CrossRef]

19. Nic-Can, G.I.; Lopez-Torres, A.; Barredo-Pool, F.; Wrobel, K.; Loyola-Vargas, V.M.; Rojas-Herrera, R.; De-la-Pena, C. New insights into somatic embryogenesis: LEAFY COTYLEDON1, BABY BOOM1 and WUSCHEL-RELATED HOMEOBOX4 are epigenetically regulated in Coffea canephora. PLoS ONE 2013, 8, e72160. [CrossRef]

20. Grzybkowska, D.; Nowak, K.; Gaj, M.D. Hypermethylation of auxin-responsive motifs in the promoters of the transcription factor genes accompanies the somatic embryogenesis induction in Arabidopsis. Int. J. Mol. Sci. 2020, 21, 6849. [CrossRef]

21. Li, W.; Liu, H.; Cheng, Z.J.; Su, Y.H.; Han, H.N.; Zhang, Y.; Zhang, X.S. DNA methylation and histone modifications regulate de novo shoot regeneration in Arabidopsis by modulating WUSCHEL expression and auxin signaling. PLoS Genet. 2011, 7, e1002243. [CrossRef]

22. Du, J.; Johnson, L.M.; Jacobsen, S.E.; Patel, D.J. DNA methylation pathways and their crosstalk with histone methylation. Nat. Rev. Mol. Cell. Biol. 2015, 16, 519-532. [CrossRef] [PubMed]

23. Ishihara, H.; Sugimoto, K.; Tarr, P.T.; Temman, H.; Kadokura, S.; Inui, Y.; Sakamoto, T.; Sasaki, T.; Aida, M.; Suzuki, T.; et al Primed histone demethylation regulates shoot regenerative competency. Nat. Commun. 2019, 10, 1786. [CrossRef] [PubMed]

24. Lee, K.; Seo, P.J. Dynamic epigenetic changes during plant regeneration. Trends Plant Sci. 2018, 23, 235-247. [CrossRef] [PubMed]

25. Lee, K.; Park, O.S.; Jung, S.J.; Seo, P.J. Histone deacetylation-mediated cellular dedifferentiation in Arabidopsis. J. Plant Physiol. 2016, 191, 95-100. [CrossRef]

26. Kim, J.Y.; Yang, W.; Forner, J.; Lohmann, J.U.; Noh, B.; Noh, Y.S. Epigenetic reprogramming by histone acetyltransferase HAG1/AtGCN5 is required for pluripotency acquisition in Arabidopsis. EMBO J. 2018, 37, e98726. [CrossRef]

27. Rymen, B.; Kawamura, A.; Lambolez, A.; Inagaki, S.; Takebayashi, A.; Iwase, A.; Sakamoto, Y.; Sako, K.; Favero, D.S.; Ikeuchi, M.; et al. Histone acetylation orchestrates wound-induced transcriptional activation and cellular reprogramming in Arabidopsis. Commun. Biol. 2019, 2, 404. [CrossRef]

28. Zhang, H.; Guo, F.; Qi, P.; Huang, Y.; Xie, Y.; Xu, L.; Han, N.; Xu, L.; Bian, H. OsHDA710-mediated histone deacetylation regulates callus formation of rice mature embryo. Plant Cell. Physiol. 2020, 61, 1646-1660. [CrossRef]

29. Wickramasuriya, A.M.; Dunwell, J.M. Global scale transcriptome analysis of Arabidopsis embryogenesis in vitro. BMC Genom. 2015, 16, 301. [CrossRef]

30. Li, H.-L.; Guo, D.; Zhu, J.-H.; Wang, Y.; Peng, S.-Q. Identification and expression analysis of genes involved in histone acetylation in Hevea brasiliensis. Tree Genet. Genomes 2017, 13, 98. [CrossRef]

31. Rodriguez-Sanz, H.; Moreno-Romero, J.; Solis, M.T.; Kohler, C.; Risueno, M.C.; Testillano, P.S. Changes in histone methylation and acetylation during microspore reprogramming to embryogenesis occur concomitantly with Bn HKMT and Bn HAT expression and are associated with cell totipotency, proliferation, and differentiation in Brassica napus. Cytogenet. Genome Res. 2014, 143, 209-218. [CrossRef]

32. Valledor, L.; Meijon, M.; Hasbun, R.; Jesus Canal, M.; Rodriguez, R. Variations in DNA methylation, acetylated histone H4, and methylated histone $\mathrm{H} 3$ during Pinus radiata needle maturation in relation to the loss of in vitro organogenic capability. J. Plant Physiol. 2010, 167, 351-357. [CrossRef]

33. Finnin, M.S.; Donigian, J.R.; Cohen, A.; Richon, V.M.; Rifkind, R.A.; Marks, P.A.; Breslow, R.; Pavletich, N.P. Structures of a histone deacetylase homologue bound to the TSA and SAHA inhibitors. Nature 1999, 401, 188-193. [CrossRef]

34. Abrahamsson, M.; Valladares, S.; Merino, I.; Larsson, E.; von Arnold, S. Degeneration pattern in somatic embryos of Pinus sylvestris L. Vitr. Cell. Dev. Biol. Plant 2017, 53, 86-96. [CrossRef]

35. Wang, H.; Enns, J.; Nelson, K.; Brost, J.; Orr, T.; Ferrie, A. Improving the efficiency of wheat microspore culture methodology: Evaluation of pretreatments, gradients, and epigenetic chemicals. Plant Cell Tissue Organ. Cult. 2019, 139, 589-599. [CrossRef]

36. Martinez, O.; Arjones, V.; Gonzalez, M.V.; Rey, M. Histone deacetylase inhibitors increase the embryogenic potential and alter the expression of embryogenesis-related and HDAC-encoding genes in grapevine (Vitis vinifera L., cv. Mencia). Plants 2021, 10, 1164. [CrossRef]

37. Tanaka, M.; Kikuchi, A.; Kamada, H. The Arabidopsis histone deacetylases HDA6 and HDA19 contribute to the repression of embryonic properties after germination. Plant Physiol. 2008, 146, 149-161. [CrossRef]

38. Wójcikowska, B.; Botor, M.; Morończyk, J.; Wójcik, A.M.; Nodzyński, T.; Karcz, J.; Gaj, M.D. Trichostatin A triggers an embryogenic transition in Arabidopsis explants via an auxin-related pathway. Front. Plant Sci. 2018, 9, 1353. [CrossRef]

39. Salaun, C.; Lepiniec, L.; Dubreucq, B. Genetic and molecular control of somatic embryogenesis. Plants 2021, 10, 1467. [CrossRef]

40. Tian, R.; Paul, P.; Joshi, S.; Perry, S.E. Genetic activity during early plant embryogenesis. Biochem. J. 2020, $477,3743-3767$. [CrossRef]

41. Lotan, T.; Ohto, M.-A.; Yee, K.M.; West, M.A.; Lo, R.; Kwong, R.W.; Yamagishi, K.; Fischer, R.L.; Goldberg, R.B.; Harada, J.J. Arabidopsis LEAFY COTYLEDON1 is sufficient to induce embryo development in vegetative cells. Cell 1998, 93, 1195-1205. [CrossRef]

42. Stone, S.L.; Kwong, L.W.; Yee, K.M.; Pelletier, J.; Lepiniec, L.; Fischer, R.L.; Goldberg, R.B.; Harada, J.J. LEAFY COTYLEDON2 encodes a B3 domain transcription factor that induces embryo development. Proc. Natl. Acad. Sci. USA 2001, 98, 11806-11811. [CrossRef] 
43. Stone, S.L.; Braybrook, S.A.; Paula, S.L.; Kwong, L.W.; Meuser, J.; Pelletier, J.; Hsieh, T.-F.; Fischer, R.L.; Goldberg, R.B.; Harada, J.J. Arabidopsis LEAFY COTYLEDON2 induces maturation traits and auxin activity: Implications for somatic embryogenesis. Proc. Natl. Acad. Sci. USA 2008, 105, 3151-3156. [CrossRef]

44. Junker, A.; Monke, G.; Rutten, T.; Keilwagen, J.; Seifert, M.; Thi, T.M.; Renou, J.P.; Balzergue, S.; Viehover, P.; Hahnel, U.; et al. Elongation-related functions of LEAFY COTYLEDON1 during the development of Arabidopsis thaliana. Plant J. 2012, 71, 427-442. [CrossRef]

45. Wójcikowska, B.; Jaskóła, K.; Gąsiorek, P.; Meus, M.; Nowak, K.; Gaj, M.D. LEAFY COTYLEDON2 (LEC2) promotes embryogenic induction in somatic tissues of Arabidopsis, via YUCCA-mediated auxin biosynthesis. Planta 2013, 238, 425-440. [CrossRef]

46. Horstman, A.; Li, M.; Heidmann, I.; Weemen, M.; Chen, B.; Muino, J.M.; Angenent, G.C.; Boutilier, K. The BABY BOOM transcription factor activates the LEC1-ABI3-FUS3-LEC2 network to induce somatic embryogenesis. Plant Physiol. 2017, 175, 848-857. [CrossRef] [PubMed]

47. Braybrook, S.A.; Harada, J.J. LECs go crazy in embryo development. Trends Plant Sci. 2008, 13, 624-630. [CrossRef]

48. Wang, H.; Caruso, L.V.; Downie, A.B.; Perry, S.E. The embryo MADS domain protein AGAMOUS-Like 15 directly regulates expression of a gene encoding an enzyme involved in gibberellin metabolism. Plant Cell 2004, 16, 1206-1219. [CrossRef]

49. Harding, E.W.; Tang, W.; Nichols, K.W.; Fernandez, D.E.; Perry, S.E. Expression and maintenance of embryogenic potential is enhanced through constitutive expression of AGAMOUS-Like 15. Plant Physiol. 2003, 133, 653-663. [CrossRef]

50. Zheng, Q.; Zheng, Y.; Ji, H.; Burnie, W.; Perry, S.E. Gene regulation by the AGL15 transcription factor reveals hormone interactions in somatic embryogenesis. Plant Physiol. 2016, 172, 2374-2387. [CrossRef]

51. Zhang, Y.; Cao, G.; Qu, L.J.; Gu, H. Involvement of an R2R3-MYB transcription factor gene AtMYB118 in embryogenesis in Arabidopsis. Plant Cell. Rep. 2009, 28, 337-346. [CrossRef]

52. Barthole, G.; To, A.; Marchive, C.; Brunaud, V.; Soubigou-Taconnat, L.; Berger, N.; Dubreucq, B.; Lepiniec, L.; Baud, S. MYB118 represses endosperm maturation in seeds of Arabidopsis. Plant Cell 2014, 26, 3519-3537. [CrossRef] [PubMed]

53. Wang, X.; Niu, Q.W.; Teng, C.; Li, C.; Mu, J.; Chua, N.H.; Zuo, J. Overexpression of PGA37/MYB118 and MYB115 promotes vegetative-to-embryonic transition in Arabidopsis. Cell. Res. 2009, 19, 224-235. [CrossRef] [PubMed]

54. Zuo, J.; Niu, Q.W.; Frugis, G.; Chua, N.H. The WUSCHEL gene promotes vegetative-to-embryonic transition in Arabidopsis. Plant J. 2002, 30, 349-359. [CrossRef] [PubMed]

55. Sablowski, R. Cytokinin and WUSCHEL tie the knot around plant stem cells. Proc. Natl. Acad. Sci. USA 2009, 106, 16016-16017. [CrossRef]

56. Su, Y.H.; Zhao, X.Y.; Liu, Y.B.; Zhang, C.L.; O'Neill, S.D.; Zhang, X.S. Auxin-induced WUS expression is essential for embryonic stem cell renewal during somatic embryogenesis in Arabidopsis. Plant J. 2009, 59, 448-460. [CrossRef]

57. Zhou, Y.; Tan, B.; Luo, M.; Li, Y.; Liu, C.; Chen, C.; Yu, C.-W.; Yang, S.; Dong, S.; Ruan, J. HISTONE DEACETYLASE19 interacts with HSL1 and participates in the repression of seed maturation genes in Arabidopsis seedlings. Plant Cell 2013, 25, 134-148. [CrossRef]

58. Ryu, H.; Cho, H.; Bae, W.; Hwang, I. Control of early seedling development by BES1/TPL/HDA19-mediated epigenetic regulation of ABI3. Nat. Commun. 2014, 5, 4138. [CrossRef]

59. Chhun, T.; Chong, S.Y.; Park, B.S.; Wong, E.C.; Yin, J.L.; Kim, M.; Chua, N.H. HSI2 repressor recruits MED13 and HDA6 to down-regulate seed maturation gene expression directly during Arabidopsis early seedling growth. Plant Cell Physiol. 2016, 57, 1689-1706. [CrossRef]

60. Gaj, M.D. Direct somatic embryogenesis as a rapid and efficient system for in vitro regeneration of Arabidopsis thaliana. Plant Cell Tissue Organ. Cult. 2001, 64, 39-46. [CrossRef]

61. Nowak, K.; Morończyk, J.; Wójcik, A.; Gaj, M.D. AGL15 controls the embryogenic reprogramming of somatic cells in Arabidopsis through the histone acetylation-mediated repression of the miRNA biogenesis genes. Int. J. Mol. Sci. 2020, 21, 6733. [CrossRef]

62. Untergasser, A.; Nijveen, H.; Rao, X.; Bisseling, T.; Geurts, R.; Leunissen, J.A. Primer3Plus, an enhanced web interface to Primer3. Nucleic Acids Res. 2007, 35, W71-W74. [CrossRef] [PubMed]

63. Luo, M.; Tai, R.; Yu, C.W.; Yang, S.; Chen, C.Y.; Lin, W.D.; Schmidt, W.; Wu, K. Regulation of flowering time by the histone deacetylase HDA5 in Arabidopsis. Plant J. 2015, 82, 925-936. [CrossRef]

64. Wójcikowska, B.; Gaj, M.D. Expression profiling of AUXIN RESPONSE FACTOR genes during somatic embryogenesis induction in Arabidopsis. Plant Cell Rep. 2017, 36, 843-858. [CrossRef] [PubMed]

65. Ruijter, J.M.; Ramakers, C.; Hoogaars, W.M.; Karlen, Y.; Bakker, O.; van den Hoff, M.J.; Moorman, A.F. Amplification efficiency: Linking baseline and bias in the analysis of quantitative PCR data. Nucleic Acids Res. 2009, 37, e45. [CrossRef] [PubMed]

66. Wolny, E.; Braszewska-Zalewska, A.; Hasterok, R. Spatial distribution of epigenetic modifications in Brachypodium distachyon embryos during seed maturation and germination. PLoS ONE 2014, 9, e101246. [CrossRef]

67. Braszzewska-Zalewska, A.; Bernas, T.; Małuszynska, J. Epigenetic chromatin modifications in Brassica genomes. Genome 2010, 53, 203-210. [CrossRef]

68. Thellin, O.; Zorzi, W.; Lakaye, B.; De Borman, B.; Coumans, B.; Hennen, G.; Grisar, T.; Igout, A.; Heinen, E. Housekeeping genes as internal standards: Use and limits. J. Biotechnol. 1999, 75, 291-295. [CrossRef]

69. Ewels, P.; Magnusson, M.; Lundin, S.; Kaller, M. MultiQC: Summarize analysis results for multiple tools and samples in a single report. Bioinformatics 2016, 32, 3047-3048. [CrossRef] 
70. Joshi, N.; Fass, J. Sickle: A Sliding-Window, Adaptive, Quality-Based Trimming Tool for FastQ Files; Version 1.33; GitHub: San Francisco, CA, USA, 2011

71. Kopylova, E.; Noe, L.; Touzet, H. SortMeRNA: Fast and accurate filtering of ribosomal RNAs in metatranscriptomic data Bioinformatics 2012, 28, 3211-3217. [CrossRef]

72. Dobin, A.; Davis, C.A.; Schlesinger, F.; Drenkow, J.; Zaleski, C.; Jha, S.; Batut, P.; Chaisson, M.; Gingeras, T.R. STAR: Ultrafast universal RNA-seq aligner. Bioinformatics 2013, 29, 15-21. [CrossRef]

73. Lassmann, T.; Hayashizaki, Y.; Daub, C.O. SAMStat: Monitoring biases in next generation sequencing data. Bioinformatics 2011, 27, 130-131. [CrossRef]

74. Okonechnikov, K.; Conesa, A.; Garcia-Alcalde, F. Qualimap 2: Advanced multi-sample quality control for high-throughput sequencing data. Bioinformatics 2016, 32, 292-294. [CrossRef] [PubMed]

75. Li, H.; Handsaker, B.; Wysoker, A.; Fennell, T.; Ruan, J.; Homer, N.; Marth, G.; Abecasis, G.; Durbin, R.; Genome Project Data Processing, S. The sequence alignment/map format and SAMtools. Bioinformatics 2009, 25, 2078-2079. [CrossRef] [PubMed]

76. Thorvaldsdottir, H.; Robinson, J.T.; Mesirov, J.P. Integrative Genomics Viewer (IGV): High-performance genomics data visualization and exploration. Brief. Bioinform. 2013, 14, 178-192. [CrossRef] [PubMed]

77. Love, M.I.; Huber, W.; Anders, S. Moderated estimation of fold change and dispersion for RNA-seq data with DESeq2. Genome Biol. 2014, 15, 550. [CrossRef] [PubMed]

78. Benjamini, Y.; Hochberg, Y. Controlling the false discovery rate: A practical and powerful approach to multiple testing. J. R Stat. Soc. Ser. B Stat. Methodol. 1995, 57, 289-300. [CrossRef]

79. Kurczyńska, E.U.; Gaj, M.D.; Ujczak, A.; Mazur, E. Histological analysis of direct somatic embryogenesis in Arabidopsis thaliana (L.) Heynh. Planta 2007, 226, 619-628. [CrossRef]

80. Pandey, R.; Müller, A.; Napoli, C.A.; Selinger, D.A.; Pikaard, C.S.; Richards, E.J.; Bender, J.; Mount, D.W.; Jorgensen, R.A. Analysis of histone acetyltransferase and histone deacetylase families of Arabidopsis thaliana suggests functional diversification of chromatin modification among multicellular eukaryotes. Nucleic Acids Res. 2002, 30, 5036-5055. [CrossRef]

81. Gaspar-Maia, A.; Alajem, A.; Meshorer, E.; Ramalho-Santos, M. Open chromatin in pluripotency and reprogramming. Nat. Rev. Mol. Cell. Biol. 2011, 12, 36-47. [CrossRef]

82. Sun, L.; Fu, X.; Ma, G.; Hutchins, A.P. Chromatin and epigenetic rearrangements in embryonic stem cell fate transitions. Front. Cell Dev. Biol. 2021, 9, 637309. [CrossRef]

83. Horstman, A.; Bemer, M.; Boutilier, K. A transcriptional view on somatic embryogenesis. Regeneration 2017, 4, 201-216. [CrossRef] [PubMed]

84. Khan, I.U.; Ali, A.; Khan, H.A.; Baek, D.; Park, J.; Lim, C.J.; Zareen, S.; Jan, M.; Lee, S.Y.; Pardo, J.M.; et al. PWR/HDA9/ABI4 complex epigenetically regulates ABA dependent drought stress tolerance in Arabidopsis. Front. Plant Sci. 2020, 11, 623. [CrossRef] [PubMed]

85. Mengel, A.; Ageeva, A.; Georgii, E.; Bernhardt, J.; Wu, K.; Durner, J.; Lindermayr, C. Nitric oxide modulates histone acetylation at stress genes by inhibition of histone deacetylases. Plant Physiol. 2017, 173, 1434-1452. [CrossRef]

86. Yang, F.; Zhang, L.; Li, J.; Huang, J.; Wen, R.; Ma, L.; Zhou, D.; Li, L. Trichostatin A and 5-azacytidine both cause an increase in global histone $\mathrm{H} 4$ acetylation and a decrease in global DNA and H3K9 methylation during mitosis in maize. BMC Plant Biol. 2010, 10, 178. [CrossRef] [PubMed]

87. Li, H.; Soriano, M.; Cordewener, J.; Muino, J.M.; Riksen, T.; Fukuoka, H.; Angenent, G.C.; Boutilier, K. The histone deacetylase inhibitor trichostatin a promotes totipotency in the male gametophyte. Plant Cell 2014, 26, 195-209. [CrossRef]

88. Jung, M.; Hoffmann, K.; Brosch, G.; Loidl, P. Analogues of trichostatin A and trapoxin B as histone deacetylase inhibitors. Bioorg. Med. Chem. Lett. 1997, 7, 1655-1658. [CrossRef]

89. Brosch, G.; Lusser, A.; Goralik-Schramel, M.; Loidl, P. Purification and characterization of a high molecular weight histone deacetylase complex (HD2) of maize embryos. Biochemistry 1996, 35, 15907-15914. [CrossRef]

90. Rodríguez, J.L.; Valledor, L.; Hasbún, R.; Sánchez, P.; Rodríguez, R.; Cañal, M.J. The effects of hormone treatment on epigenetic marks during organogenesis in Pinus radiata D. Don embryos. J. Plant Growth Regul. 2016, 35, 97-108. [CrossRef]

91. Law, R.D.; Suttle, J.C. Chromatin remodeling in plant cell culture: Patterns of DNA methylation and histone H3 and H4 acetylation vary during growth of asynchronous potato cell suspensions. Plant Physiol. Biochem. 2005, 43, 527-534. [CrossRef]

92. Anzola, J.M.; Sieberer, T.; Ortbauer, M.; Butt, H.; Korbei, B.; Weinhofer, I.; Mullner, A.E.; Luschnig, C. Putative Arabidopsis transcriptional adaptor protein (PROPORZ1) is required to modulate histone acetylation in response to auxin. Proc. Natl. Acad. Sci. USA 2010, 107, 10308-10313. [CrossRef]

93. Weiste, C.; Droge-Laser, W. The Arabidopsis transcription factor bZIP11 activates auxin-mediated transcription by recruiting the histone acetylation machinery. Nat. Commun. 2014, 5, 3883. [CrossRef]

94. Kuhn, A.; Ramans Harborough, S.; McLaughlin, H.M.; Natarajan, B.; Verstraeten, I.; Friml, J.; Kepinski, S.; Ostergaard, L. Direct ETTIN-auxin interaction controls chromatin states in gynoecium development. Elife 2020, 9, e51787. [CrossRef] [PubMed]

95. Nguyen, C.T.; Tran, G.B.; Nguyen, N.H. Homeostasis of histone acetylation is critical for auxin signaling and root morphogenesis. Plant Mol. Biol. 2020, 103, 1-7. [CrossRef] [PubMed]

96. Brasszewska-Zalewska, A.J.; Wolny, E.A.; Śmiałek, Ł.; Hasterok, R. Tissue-specific epigenetic modifications in root apical meristem cells of Hordeum vulgare. PLoS ONE 2013, 8, e69204. [CrossRef] [PubMed] 
97. Santamaria, M.E.; Hasbun, R.; Valera, M.J.; Meijon, M.; Valledor, L.; Rodriguez, J.L.; Toorop, P.E.; Canal, M.J.; Rodriguez, R. Acetylated H4 histone and genomic DNA methylation patterns during bud set and bud burst in Castanea sativa. J. Plant Physiol. 2009, 166, 1360-1369. [CrossRef] [PubMed]

98. Meijón, M.; Feito, I.; Valledor, L.; Rodríguez, R.; Cañal, M.J. Dynamics of DNA methylation and Histone H4 acetylation during floral bud differentiation in azalea. BMC Plant Biol. 2010, 10, 1-14. [CrossRef]

99. Kawakatsu, T.; Stuart, T.; Valdes, M.; Breakfield, N.; Schmitz, R.J.; Nery, J.R.; Urich, M.A.; Han, X.; Lister, R.; Benfey, P.N.; et al. Unique cell-type-specific patterns of DNA methylation in the root meristem. Nat. Plants 2016, 2, 16058. [CrossRef] [PubMed]

100. You, Y.; Sawikowska, A.; Neumann, M.; Pose, D.; Capovilla, G.; Langenecker, T.; Neher, R.A.; Krajewski, P.; Schmid, M. Temporal dynamics of gene expression and histone marks at the Arabidopsis shoot meristem during flowering. Nat. Commun. 2017, 8, 15120. [CrossRef]

101. Elhiti, M.; Stasolla, C. Ectopic expression of the Brassica SHOOTMERISTEMLESS attenuates the deleterious effects of the auxin transport inhibitor TIBA on somatic embryo number and morphology. Plant Sci. 2011, 180, 383-390. [CrossRef]

102. Thomas, C.; Bronner, R.; Molinier, J.; Prinsen, E.; van Onckelen, H.; Hahne, G. Immuno-cytochemical localization of indole-3-acetic acid during induction of somatic embryogenesis in cultured sunflower embryos. Planta 2002, 215, 577-583. [CrossRef]

103. Karami, O.; Philipsen, C.; Rahimi, A.; Nurillah, A.R.; Boutilier, K.; Offringa, R. Endogenous auxin directs development of embryonic stem cells into somatic proembryos in Arabidopsis. bioRxiv 2021. [CrossRef]

104. Peng, M.; Li, Z.; Zhou, N.; Ma, M.; Jiang, Y.; Dong, A.; Shen, W.H.; Li, L. Linking PHYTOCHROME-INTERACTING FACTOR to histone modification in plant shade avoidance. Plant Physiol. 2018, 176, 1341-1351. [CrossRef] [PubMed]

105. van der Woude, L.C.; Perrella, G.; Snoek, B.L.; van Hoogdalem, M.; Novak, O.; van Verk, M.C.; van Kooten, H.N.; Zorn, L.E.; Tonckens, R.; Dongus, J.A.; et al. HISTONE DEACETYLASE 9 stimulates auxin-dependent thermomorphogenesis in Arabidopsis thaliana by mediating H2A.Z depletion. Proc. Natl. Acad. Sci. USA 2019, 116, 25343-25354. [CrossRef] [PubMed]

106. Karami, O.; Rahimi, A.; Mak, P.; Horstman, A.; Boutilier, K.; Compier, M.; van der Zaal, B.; Offringa, R. An Arabidopsis AT-hook motif nuclear protein mediates somatic embryogenesis and coinciding genome duplication. Nat. Commun. 2021, $12,2508$. [CrossRef]

107. Wang, L.; Qiao, H. Chromatin regulation in plant hormone and plant stress responses. Curr. Opin. Plant Biol. 2020, 57, 164-170. [CrossRef]

108. Yang, H.; Liu, X.; Xin, M.; Du, J.; Hu, Z.; Peng, H.; Rossi, V.; Sun, Q.; Ni, Z.; Yao, Y. Genome-wide mapping of targets of maize histone deacetylase HDA101 reveals its function and regulatory mechanism during seed development. Plant Cell 2016, 28, 629-645. [CrossRef]

109. Boycheva, I.; Vassileva, V.; Iantcheva, A. Histone acetyltransferases in plant development and plasticity. Curr. Genom. 2014, 15, 28. [CrossRef]

110. Chen, X.; Ding, A.B.; Zhong, X. Functions and mechanisms of plant histone deacetylases. Sci. China Life Sci. 2020, 63, 206-216. [CrossRef]

111. Zhou, L.; Yarra, R.; Jin, L.; Yang, Y.; Cao, H.; Zhao, Z. Identification and expression analysis of histone modification gene (HM) family during somatic embryogenesis of oil palm. BMC Genom. 2022, 23. [CrossRef]

112. Ma, X.; Zhang, C.; Zhang, B.; Yang, C.; Li, S. Identification of genes regulated by histone acetylation during root development in Populus trichocarpa. BMC Genom. 2016, 17, 96. [CrossRef]

113. Imran, M.; Shafiq, S.; Farooq, M.A.; Naeem, M.K.; Widemann, E.; Bakhsh, A.; Jensen, K.B.; Wang, R.R. Comparative genome-wide analysis and expression profiling of histone acetyltransferase (HAT) gene family in response to hormonal applications, metal and abiotic stresses in cotton. Int. J. Mol. Sci. 2019, 20, 5311. [CrossRef] [PubMed]

114. Imran, M.; Shafiq, S.; Naeem, M.K.; Widemann, E.; Munir, M.Z.; Jensen, K.B.; Wang, R.R. Histone deacetylase (HDAC) gene family in allotetraploid cotton and its diploid progenitors: In silico identification, molecular characterization, and gene expression analysis under multiple abiotic stresses, DNA damage and phytohormone treatments. Int. J. Mol. Sci. 2020, 21, 321. [CrossRef] [PubMed]

115. Chow, C.N.; Lee, T.Y.; Hung, Y.C.; Li, G.Z.; Tseng, K.C.; Liu, Y.H.; Kuo, P.L.; Zheng, H.Q.; Chang, W.C. PlantPAN3.0: A new and updated resource for reconstructing transcriptional regulatory networks from ChIP-seq experiments in plants. Nucleic Acids Res. 2019, 47, D1155-D1163. [CrossRef] [PubMed]

116. Wójcik, A.M.; Wójcikowska, B.; Gaj, M.D. Current perspectives on the auxin-mediated genetic network that controls the induction of somatic embryogenesis in plants. Int. J. Mol. Sci. 2020, 21, 1333. [CrossRef] [PubMed]

117. Cigliano, R.A.; Cremona, G.; Paparo, R.; Termolino, P.; Perrella, G.; Gutzat, R.; Consiglio, M.F.; Conicella, C. Histone deacetylase AtHDA7 is required for female gametophyte and embryo development in Arabidopsis. Plant Physiol. 2013, 163, 431-440. [CrossRef]

118. Boycheva, I.; Vassileva, V.; Revalska, M.; Zehirov, G.; Iantcheva, A. Different functions of the histone acetyltransferase HAC1 gene traced in the model species Medicago truncatula, Lotus japonicus and Arabidopsis thaliana. Protoplasma 2017, 254, 697-711. [CrossRef]

119. Zhou, C.; Labbe, H.; Sridha, S.; Wang, L.; Tian, L.; Latoszek-Green, M.; Yang, Z.; Brown, D.; Miki, B.; Wu, K. Expression and function of HD2-type histone deacetylases in Arabidopsis development. Plant J. 2004, 38, 715-724. [CrossRef]

120. Kim, W.; Latrasse, D.; Servet, C.; Zhou, D.X. Arabidopsis histone deacetylase HDA9 regulates flowering time through repression of AGL19. Biochem. Biophys. Res. Commun. 2013, 432, 394-398. [CrossRef] 
121. Zhang, F.; Wang, L.; Ko, E.E.; Shao, K.; Qiao, H. Histone deacetylases SRT1 and SRT2 interact with ENAP1 to mediate ethyleneinduced transcriptional repression. Plant Cell 2018, 30, 153-166. [CrossRef]

122. Xiao, J.; Zhang, H.; Xing, L.; Xu, S.; Liu, H.; Chong, K.; Xu, Y. Requirement of histone acetyltransferases HAM1 and HAM2 for epigenetic modification of FLC in regulating flowering in Arabidopsis. J. Plant Physiol. 2013, 170, 444-451. [CrossRef]

123. Gliwicka, M.; Nowak, K.; Balazadeh, S.; Mueller-Roeber, B.; Gaj, M.D. Extensive modulation of the transcription factor transcriptome during somatic embryogenesis in Arabidopsis thaliana. PLoS ONE 2013, 8, e69261. [CrossRef] [PubMed]

124. Servet, C.; Conde e Silva, N.; Zhou, D.X. Histone acetyltransferase AtGCN5/HAG1 is a versatile regulator of developmental and inducible gene expression in Arabidopsis. Mol. Plant 2010, 3, 670-677. [CrossRef] [PubMed]

125. Vlachonasios, K.; Poulios, S.; Mougiou, N. The histone acetyltransferase GCN5 and the associated coactivators ADA2: From evolution of the SAGA complex to the biological roles in plants. Plants 2021, 10, 308. [CrossRef] [PubMed]

126. Gao, M.J.; Li, X.; Huang, J.; Gropp, G.M.; Gjetvaj, B.; Lindsay, D.L.; Wei, S.; Coutu, C.; Chen, Z.; Wan, X.C.; et al. SCARECROWLIKE15 interacts with HISTONE DEACETYLASE19 and is essential for repressing the seed maturation programme. Nat. Commun. 2015, 6, 7243. [CrossRef]

127. Vlachonasios, K.E.; Thomashow, M.F.; Triezenberg, S.J. Disruption mutations of $A D A 2 b$ and GCN5 transcriptional adaptor genes dramatically affect Arabidopsis growth, development, and gene expression. Plant Cell 2003, 15, 626-638. [CrossRef]

128. Tian, L.; Fong, M.P.; Wang, J.J.; Wei, N.E.; Jiang, H.; Doerge, R.; Chen, Z.J. Reversible histone acetylation and deacetylation mediate genome-wide, promoter-dependent and locus-specific changes in gene expression during plant development. Genetics 2005, 169, 337-345. [CrossRef]

129. Poulios, S.; Vlachonasios, K.E. Synergistic action of GCN5 and CLAVATA1 in the regulation of gynoecium development in Arabidopsis thaliana. New Phytol. 2018, 220, 593-608. [CrossRef]

130. Benhamed, M.; Martin-Magniette, M.L.; Taconnat, L.; Bitton, F.; Servet, C.; De Clercq, R.; De Meyer, B.; Buysschaert, C.; Rombauts, S.; Villarroel, R.; et al. Genome-scale Arabidopsis promoter array identifies targets of the histone acetyltransferase GCN5. Plant J. 2008, 56, 493-504. [CrossRef]

131. Aquea, F.; Timmermann, T.; Herrera-Vasquez, A. Chemical inhibition of the histone acetyltransferase activity in Arabidopsis thaliana. Biochem. Biophys. Res. Commun. 2017, 483, 664-668. [CrossRef]

132. Benhamed, M.; Bertrand, C.; Servet, C.; Zhou, D.X. Arabidopsis GCN5, HD1, and TAF1/HAF2 interact to regulate histone acetylation required for light-responsive gene expression. Plant Cell 2006, 18, 2893-2903. [CrossRef]

133. Szemenyei, H.; Hannon, M.; Long, J.A. TOPLESS mediates auxin-dependent transcriptional repression during Arabidopsis embryogenesis. Science 2008, 319, 1384-1386. [CrossRef] [PubMed]

134. Wu, M.F.; Yamaguchi, N.; Xiao, J.; Bargmann, B.; Estelle, M.; Sang, Y.; Wagner, D. Auxin-regulated chromatin switch directs acquisition of flower primordium founder fate. Elife 2015, 4, e09269. [CrossRef] [PubMed]

135. Chung, Y.; Zhu, Y.; Wu, M.F.; Simonini, S.; Kuhn, A.; Armenta-Medina, A.; Jin, R.; Ostergaard, L.; Gillmor, C.S.; Wagner, D. Auxin Response Factors promote organogenesis by chromatin-mediated repression of the pluripotency gene SHOOTMERISTEMLESS. Nat. Commun. 2019, 10, 886. [CrossRef] [PubMed]

136. Roosjen, M.; Paque, S.; Weijers, D. Auxin Response Factors: Output control in auxin biology. J. Exp. Bot 2018, 69, 179-188. [CrossRef]

137. Causier, B.; Ashworth, M.; Guo, W.; Davies, B. The TOPLESS interactome: A framework for gene repression in Arabidopsis. Plant Physiol. 2012, 158, 423-438. [CrossRef] 